\title{
PROSOPOGRAFIA A PARTIR DA WEB: AVALIANDO E MENSURANDOAS FONTES PARA O ESTUDO DAS ELITES PARLAMENTARES BRASILEIRAS NA INTERNET ${ }^{1}$
}

\author{
Sérgio Soares Braga
}

\author{
Maria Alejandra Nicolás
}

\begin{abstract}
RESUMO
O objetivo deste artigo é fazer uma avaliação das informações disponíveis nos portais das assembléias legislativas brasileiras sobre os deputados estaduais e distritais brasileiros da legislatura de 2003-2007, e apresentar uma proposta de construção de um indicador para avaliar e mensurar o grau de disponibilidade das informações sobre tais atores na web. A partir da aplicação desse indicador, avaliaremos o rendimento analítico do emprego do enfoque das biografias coletivas utilizando como fonte exclusiva os portais das casas legislativas brasileiras. Procuraremos demonstrar a proposição segundo a qual, devido ao insuficiente grau de transparência dos portais eletrônicos da maior parte das assembléias legislativas, o uso exclusivo ou predominante de tal fonte não é recomendável para o conhecimento e monitoramento da ação política das elites que delas fazem parte, inversamente ao que ocorre com a Câmara dos Deputados brasileira.
\end{abstract}

PALAVRAS-CHAVE: Elites parlamentares brasileiras; biografias coletivas; internet $e$ política; websites legislativos.

\section{INTRODUÇÃO}

O objetivo deste texto é fazer uma avaliação do uso das tecnologias de informação e de comunicação (TICs) pelas elites parlamentares brasileiras - no caso, os deputados estaduais no exercício do mandato no segundo semestre de 2006 - e construir um perfil sociopolítico dessas elites a

\footnotetext{
1 Este artigo é parte de uma pesquisa em andamento intitulada "Proposopografia a partir da web: avaliando e monitorando as elites políticas brasileiras e sul-americanas por meio dos sites da internet" que desenvolvemos no Departamento de Ciências Sociais da Universidade Federal do Paraná (UFPR), juntamente com a bolsista UFPR-Tesouro Nacional (TN) Letícia Carina Cruz. Agradecemos imensamente aos estudantes de graduação e pesquisadores Hugo Loss e Fernando Baptista Leite pelo auxílio prestado na fase final de elaboração deste trabalho; sem a sua preciosa ajuda o texto não poderia ser concluído, motivo pelo qual gostaríamos de deixar consignados nossos agradecimentos ao esforço voluntário desses estudantes. Uma versão preliminar do texto foi apresentada no $31^{\circ}$ Encontro Anual da Associação Nacional de Pós-Graduação e Pesquisa em Ciências Sociais (Anpocs) realizado em outubro de 2007, no Seminário Temático “Elites e instituições políticas”, coordenado pelos professores Renato Monseff Perissinotto (UFPR) e Miguel Serna (Universidade Federal do Rio Grande do Sul (UFRGS)), a quem agradecemos as observações críticas.
}

partir das informações encontradas nos portais legislativos. Buscaremos também apresentar uma proposta de construção de um indicador para avaliar o grau de disponibilidade das informações sobre tais elites na web, especialmente nos portais das casas legislativas em que atuam tais parlamentares. Procuraremos cumprir esse objetivo por meio da elaboração e da análise de uma planilha prosopográfica contendo as biografias coletivas dos 1059 deputados estaduais eleitos para a $15^{\mathrm{a}}$ Legislatura das assembléias e câmaras legislativas brasileiras (ou seja, do período 2003-2007), utilizando exclusivamente as fontes encontradas na internet, em que buscamos organizar as informações sobre as seguintes dimensões da atividade de tais parlamentares: 1) perfil social e biográfico (abrangendo itens como cor da pele; idade; gênero; nível educacional; profissão e estrato social); 2) trajetória política (forma de entrada na política; cargos administrativos e eletivos anteriormente ocupados; filiações partidárias anteriores; vínculos com associações e movimentos sociais, dentre outras atividades) e 3) comportamento político (proposições apresentadas e aprovadas; comportamento durante as votações nominais; índice de presença em plenário; disponibilidade de portais eletrônicos; informações sobre o uso de verbas indenizatórias etc.). 
A partir desses objetivos de ordem mais geral, buscaremos cumprir dois objetivos específicos: a) apresentar uma proposta de mensuração do grau em que as informações sobre os parlamentares estão presentes nos portais das casas legislativas; b) elaborar e aplicar instrumentos teóricometodológicos para a análise de tais dados, bem como para a avaliação do significado analítico de tais informações para o estudo das elites parlamentares nas unidades subnacionais brasileiras. Por fim, seguindo metodologia já aplicada em estudos por nós elaborados anteriormente (BRAGA, 2007a), procuraremos sugerir um índice para mensurar o grau em que tais informações sobre as elites parlamentares estão disponíveis em cada uma das casas legislativas examinadas, analisando o comportamento desse índice por cada unidade da federação brasileira (estados e Distrito Federal).

Nesse sentido, devemos esclarecer que, menos do que uma investigação exaustiva sobre as características em si dos perfis e dos padrões de recrutamento de tais elites parlamentares, interessa-nos mapear que tipo de informação pode-se obter e até onde pode chegar a análise política a partir dos dados disponíveis sobre tais atores nos portais dos órgãos legislativos brasileiros, conforme eles encontravam-se organizados e disponíveis nos portais eletrônicos das assembléias legislativas brasileiras no segundo semestre de 2006. Subsidiariamente, procuraremos tecer algumas considerações sobre o rendimento analítico do uso do método das biografias coletivas para o estudo sistemático das elites parlamentares a partir dos portais das casas legislativas vis-à-vis outras técnicas de análise empregadas para o estudo deste objeto.

Com efeito, embora já exista um corpo razoável de estudos sobre o recrutamento e o perfil sociopolítico das elites políticas brasileiras de uma forma geral e de suas elites parlamentares em particular $^{2}$, poucos desses estudos buscam avaliar 0

\footnotetext{
2 Dentre esses estudos mais recentes sobre as elites políticas e parlamentares brasileiras, além de vários perfis biográficos publicados por instituições especializadas (Departamento Intersindical de Assessoria Parlamentar (DIAP), agências de análise política, casas legislativas), devemos destacar os trabalhos de Marenco (2000), Messenberg (2002; 2007), Rodrigues (2002; 2006) e Marenco e Serna (2007) no que se refere aos legislativos nacionais, e de Lima Jr. e Camargo (1997), Anastasia, Correia e Nunes (2005) e Rodrigues (2006) para as unidades subnacionais de governo.
}

uso que tais atores fazem da web para interagir e comunicar-se com o eleitor ou utilizar as fontes disponíveis na internet para divulgar suas atividades para a opinião pública. Por outro lado, os poucos estudos existentes sobre a relação entre internet e elites parlamentares (CARDOSO \& MORGADO, 2003; DADER, 2003; CUNHA, 2005; MARQUES, 2007) geralmente relegam a segundo plano as questões relacionadas aos perfis sociais e às características do "recrutamento" de tais elites, centrando seu foco de atenção no problema da interação ou dos "graus de participação" do eleitor em relação aos processos decisórios nos quais ele está inserido.

Neste artigo, buscaremos articular esses dois níveis de análise, na medida em que procuraremos efetuar uma caracterização dos perfis dos parlamentares utilizando apenas as informações disponíveis na internet e nos portais das casas legislativas. Com isso, procuraremos integrar duas áreas de pesquisa geralmente separadas nos estudos sobre as elites políticas, especialmente as elites parlamentares: i) por um lado, os estudos sociológicos sobre recrutamento, perfil, valores e comportamento político-ideológico de tais elites; ii) por outro lado, os estudos sobre como tais elites dirigentes comunicam-se e interagem com a opinião pública e com os cidadãos de uma maneira geral por meio dos recursos dos meios de comunicação. O suposto de tal reflexão é que a disponibilidade de tais informações na web é um fator de fundamental importância para o estreitamento das relações entre representantes e representados, bem como para a promoção de maior accountability do sistema político e dos atores nele atuantes para com os eleitores e os cidadãos de maneira geral.

Sublinhamos que tal objetivo compatibiliza-se com a premissa teórico-metodológica mais geral que nos orienta: conforme observado por alguns autores cujas contribuições constituem o pano de fundo mais geral do presente texto (NORRIS, 2001; CASTELLS, 2003) e por nós mesmos em outros trabalhos (BRAGA, 2007a; 2007b), as ferramentas utilizadas pela internet, desde que adequadamente utilizadas, podem ser um importante instrumento não só de conhecimento das elites dirigentes pelos pesquisadores e pelo público especializado, mas também de controle e monitoramento de tais atores e da esfera pública de uma forma geral pelos cidadãos e não apenas dos órgãos legislativos. 
O método que utilizaremos será o prosopográfico, que já empregamos anteriormente em trabalhos sobre perfis de elites parlamentares (BRAGA, 1998; 2002) e que também tem sido utilizado por uma série de outros analistas para o estudo de "elites" e/ou grupos de intervenção política no Brasil ${ }^{3}$. Entretanto, como já observamos, diferentemente de outros trabalhos de natureza análoga que empregam tal recurso metodológico, utilizaremos única e exclusivamente, para os fins deste artigo, os materiais contidos sobre os parlamentares nos portais legislativos no final da $15^{\mathrm{a}}$ Legislatura, no segundo semestre de 2006. Isso se deve ao fato de que o nosso objetivo precípuo não é elaborar um perfil, por si só, dessas elites parlamentares, mas efetuar uma reflexão de cunho teórico-metodológico acerca da eficácia da internet como recurso para o estudo e o acompanhamento da atividade social de tais elites, bem como de sua comunicação com os cidadãos ${ }^{4}$.

3 Conforme a definição clássica da Lawrence Stone, "A prosopografia é a investigação das características comuns do passado de um grupo de atores na história através do estudo coletivo de suas vidas. O método empregado consiste em definir um universo a ser estudado e então a ele formular um conjunto de questões padronizadas - sobre nascimento e morte, casamento e família, origens sociais e posições econômicas herdadas, local de residência, educação e fonte de riqueza pessoal, ocupação, religião, experiência profissional e assim por diante [...]. O propósito da prosopografia é dar sentido à ação política, ajudar a explicar a mudança ideológica ou cultural, identificar a realidade social, descrever e analisar com precisão a estrutura da sociedade e o grau e a natureza dos movimentos que se dão no seu interior" (Stone apud HEINZ, 2006, p. 9; sem grifos no original). Heinz (2006) contém um amplo apanhado bibliográfico, teórico e aplicado, sobre o conceito e para o qual remetemos o leitor interessado em aprofundar-se na temática. Estranhamente, no entanto, esse texto de Lawrence Stone ainda não foi traduzido para o português.

${ }^{4}$ Via de regra, quando se emprega o método prosopográfico para análises sociológicas de grupos de intervenção política as principais fontes de pesquisa utilizadas geralmente são dicionários biográficos e perfis das casas legislativas (FLEISCHER, 1976; MARENCO, 2000), dados oficiais divulgados pelo TSE e pelos tribunais regionais eleitorais (TREs) (RODRIGUES, 2006), biografias e memórias dos próprios membros da elites examinadas (MICELI, 1976; LOVE, 1982) ou outros recursos como questionários e surveys aplicados aos membros das elites examinadas (PERISSINOTTO et alii, 2006). De nosso conhecimento, ainda são virtualmente inexistentes estudos que busquem problematizar a internet como fonte única ou mesmo principal do estudo de um determinado segmento de tais elites.
Por fim, procuraremos analisar algumas poucas variáveis de maneira mais intensiva, a fim de tomá-las como exemplo e ilustração do tipo de abordagem a ser ulteriormente desenvolvida de maneira mais aprofundada em outros trabalhos. Assim, não é nosso objetivo neste texto efetuar um estudo exaustivo de todos os problemas levantados, mas indicar diretrizes de pesquisa e apresentar algumas evidências para dar início a uma discussão mais aprofundada e substantiva sobre os impactos das TICs em múltiplas dimensões dos sistemas políticos contemporâneos, especialmente acerca do papel e da eficácia da internet no controle dos representantes pelos representados.

Assim sendo, ao examinar os dados da $15^{\mathrm{a}}$ Legislatura, desejamos apresentar os resultados de nossa pesquisa sobre a mais recente legislatura das assembléias legislativas brasileiras, possibilitando uma análise do "grau de disponibilidade” de informações sobre as elites parlamentares nos portais legislativos, bem como contribuir para a criação de uma metodologia de coleta, monitoramento e análise sistemática de tais informações. Reitere-se novamente que não é nosso objetivo traçar um perfil exaustivo de todos os parlamentares empossados ao longo da legislatura, mas apenas daqueles que ocuparam as cadeiras parlamentares durante o período pesquisado, ou seja, entre os meses de outubro e dezembro de 2006, quando foi efetuada a coleta de dados de nossa pesquisa.

Para cumprir esses objetivos, organizaremos nossa exposição da seguinte forma: 1) inicialmente, definiremos o universo empírico pesquisado e esclareceremos alguns aspectos da metodologia empregada em nossa pesquisa; 2) em seguida, avaliaremos as informações contidas nos portais das assembléias legislativas brasileiras sobre o "perfil social" dos deputados estaduais, tantos de seus "atributos inatos", quanto de seus atributos "adquiridos”; 3) avaliaremos as informações disponíveis nos portais das assembléias sobre a trajetória política pregressa dos deputados, ou seja, de sua atuação ou "socialização" política antes de assumirem os mandatos nas casas legislativas e 4) avaliaremos as informações disponíveis nos portais sobre os itens que julgamos estar mais diretamente relacionadas ao "comportamento político" dos deputados, tanto aquelas que podem ser obtidos diretamente pelo cidadão-internauta por meio dos perfis individuais dos deputados quanto aquelas que estão acessíveis exclusivamente por meio dos portais dos parlamentares. 
Como corolário das análises efetuadas em cada item buscaremos elaborar um indicador quantitativo das informações disponíveis sobre as elites parlamentares em cada casa legislativa e que possibilite aos cidadãos e aos pesquisadores de maneira geral o monitoramento e o acompanhamento quotidianos da atualização de tais informações nos portais das assembléias. Tal indicador pode ser tomado também, indiretamente, como um "índice de transparência” de cada casa legislativa no tocante à disponibilidade de informações sobre as elites parlamentares que nelas atuam.

\section{O UNIVERSO EMPÍRICO DA PESQUISAE A METODOLOGIA EMPREGADA}

Ao todo foram pesquisados 1059 deputados que exerciam seus mandatos nos legislativos estaduais brasileiros no segundo semestre de 2006, dis- tribuídos em um total de 29 legendas. A coleta dos dados nesse período deveu-se ao fato de que nossa intenção era analisar de maneira sistemática dados sobre migração partidária e variação dos percentuais de legendas entre os vários partidos e blocos partidários ao longo da legislatura. Para as assembléias que estavam fora do ar durante todo o período pesquisado (Alagoas e Rondônia), coletamos dados do Tribunal Superior Eleitoral (TSE) sobre o nome e a filiação partidária dos deputados. A partir dos dados coletados exclusivamente nesses portais montamos uma planilha prosopográfica contendo informações sobre as "biografias coletivas" de todos os parlamentares pesquisados. A distribuição do quadro partidário pelas regiões durante 0 período pesquisado, acompanhadas das variações de deputados na legenda do partido em comparação com a bancada da posse, é dada pela Tabela 1.

TABELA1-DISTRIBUIÇÃO DOS PARTIDOS POR REGIÃO NASASSEMBLÉIAS LEGISLATIVAS BRASILEIRAS (SEGUNDO SEMESTRE DE 2006)

\begin{tabular}{|c|c|c|c|c|c|c|c|c|c|c|c|c|c|c|c|c|c|c|}
\hline & \multicolumn{3}{|c|}{$\begin{array}{l}\text { CENTRO- } \\
\text { OESTE }\end{array}$} & \multicolumn{3}{|c|}{ NORDE STE } & \multicolumn{3}{|c|}{ NORTE } & \multicolumn{3}{|c|}{ SUDESTE } & \multicolumn{3}{|c|}{ SUL } & \multicolumn{3}{|c|}{ TOTAL } \\
\hline & $\mathbf{H}$ & $\%$ & $\Delta \%$ & $\mathbf{H}$ & $\%$ & $\Delta \%$ & $\mathbf{H}$ & $\%$ & $\Delta \%$ & $\mathbf{H}$ & $\%$ & $\Delta \%$ & H & $\%$ & $\Delta \%$ & H & $\%$ & $\Delta$ \\
\hline PSDB & 19 & 16,8 & $-4,4$ & 49 & 14,4 & 0,6 & 25 & 13,5 & 2,1 & 49 & 18,1 & 5,2 & 16 & 10,7 & 3,3 & 158 & 14,9 & 20 \\
\hline PMDE & 27 & 23,9 & 7,1 & 36 & 10,6 & $-1,1$ & 28 & 15,1 & 1,6 & 31 & 11,4 & 1,4 & 31 & 20,8 & 4,7 & 153 & 14,4 & 18 \\
\hline PT & 16 & 14,2 & 1,8 & 31 & 9,1 & $-0,6$ & 20 & 10,8 & 0,5 & 46 & 17,0 & $-1,5$ & 28 & 18,8 & $-2,0$ & 141 & 13,3 & -6 \\
\hline PFL & 12 & 10,6 & 2,6 & 64 & 18,8 & 1,5 & 14 & 7,6 & $-1,6$ & 24 & 8,9 & 1,9 & 15 & 10,1 & $-0,6$ & 129 & 12,2 & 9 \\
\hline ppd & 4 & 3,5 & $-8,0$ & 51 & 15 & 3,3 & 27 & 14,6 & $-1,6$ & 24 & 8,9 & $-0,7$ & 2 & 1,3 & $-1,4$ & 108 & 10,2 & -5 \\
\hline PDT & 8 & 7,1 & 3,6 & 25 & 7,3 & 1,7 & 12 & 6,5 & 0,6 & 22 & 8,1 & 2,6 & 14 & 9,4 & 0,7 & 81 & 7,6 & 19 \\
\hline PP & 7 & 6,2 & 0,0 & 16 & 4,7 & $-3,5$ & 11 & 5,9 & 0,0 & 12 & 4,4 & $-4,1$ & 20 & 13,4 & $-2,7$ & 66 & 6,2 & -27 \\
\hline РT日 & 5 & 4,4 & 0,9 & 15 & 4,4 & $-0,9$ & 10 & 5,4 & $-1,6$ & 14 & 5,2 & $-0,3$ & 9 & 6 & $-1,4$ & 53 & 5,0 & -8 \\
\hline PPS & 8 & 7,1 & 2,7 & 10 & 2,9 & $-1,2$ & 11 & 5,9 & 2,7 & 15 & 5,5 & 1,8 & 6 & 4 & 0,0 & 50 & 4,7 & 9 \\
\hline PSB & 0 & 0 & $-3,5$ & 22 & 6,5 & 0,9 & 5 & 2,7 & $-2,2$ & 14 & 5,2 & $-3,3$ & 4 & 2,7 & $-0,7$ & 45 & 4,2 & -15 \\
\hline PL & 6 & 5,3 & $-1,8$ & 14 & 4,1 & $-1,2$ & 12 & 6,5 & $-2,7$ & 9 & 3,3 & $-2,2$ & 2 & 1,3 & $-0,7$ & 43 & 4,1 & -18 \\
\hline ppe & 1 & 0,9 & $-0,9$ & 8 & 2,3 & 0,5 & 10 & 5,4 & 2,2 & 11 & 4,1 & $-0,7$ & 2 & 1,3 & 0,6 & 32 & 3,0 & 4 \\
\hline Total & 113 & 100 & 0,0 & 341 & 100 & 0,0 & 185 & 100 & 0,0 & 271 & 100 & 0,0 & 149 & 100 & 0,0 & 1059 & 100 & 0 \\
\hline
\end{tabular}

FONTES: o autor, a partir de TSE (2008) e de Braga (2007b).

NOTAS: 1. PSDB: Partido da Social-Democracia Brasileira; PMDB: Partido do Movimento Democrático

Brasileiro; PT: Partido dos Trabalhadores; PFL: Partido da Frente Liberal; PDT: Partido Democrático Trabalhista; PP: Partido Progressista; PTB: Partido Trabalhista Brasileiro; PPS: Partido Popular Socialista; PSB: Partido Socialista Brasileiro; PL: Partido Liberal.

2. PPD: Pequenos Partidos de Direita: Partido dos Aposentados da Nação (PAN), Partido Humanista Social (PHS), Partido da Mobilização Nacional (PMN), Partido Republicano Brasileiro (PRB), Partido da Reconstrução da Ordem Nacional (Prona), Partido Republicano Progressista (PRP), Partido Renovador Trabalhista Brasileiro (PRTB), Partido Social Cristão (PSC), Partido Social Democrático (PSD), Partido Social-Democrata Cristão (PSDC), Partido Social Liberal (PSL), Partido Social Trabalhista (PST), Partido dos Trabalhadores do Brasil (PTdoB), Partido Trabalhista Nacional (PTN).

3. PPE: Pequenos partidos de esquerda: Partido Comunista do Brasil (PCdoB), Partido Verde (PV) e Partido Socialismo e Liberdade (PSOL).

4. O PSOL obteve o registro definitivo no TSE em setembro de 2005, não tendo lançado candidatos ao pleito de 2002.

Pela tabela acima podemos perceber que, apesar das migrações partidárias ocorridas ao longo da legislatura e das repercussões políticas do "escândalo do mensalão”, na segunda metade do primeiro presidencial mandato de Luís Inácio Lula da Silva (2002-2006), não houve alterações signi- ficativas ao longo da legislatura nas posições relativas dos partidos representados nos legislativos estaduais. Destaque-se a esse respeito o PSDB, que começou a legislatura como o segundo maior partido, com 138 deputados estaduais - logo após o PT - e terminou como o maior partido, com um 
total de 158 parlamentares. Foi também o partido que apresentou maior ganho de deputados ao longo da legislatura, como um total de 20 parlamentares. Já o PT, seu principal adversário programático, começou a legislatura como o maior partido representado nos legislativos estaduais brasileiros, com um total de 147 deputados, terminado a legislatura como o terceiro maior partido, com uma perda percentual de $0,6 \%$ parlamentares - um número que podemos considerar bastante reduzido, se considerarmos os altos impactos nos meios de comunicação dos escândalos de corrupção envolvendo a legenda. Outro dado que deve ser destacado da tabela acima é o elevado percentual da bancada dos "pequenos partidos de direita" (ppd) nos legislativos estaduais brasileiros $(10,2 \%)$ em contraste com o reduzido número de "pequenos partidos de esquerda” (ppe), que possuem apenas 32 deputados estaduais do total de $1059(3,0 \%)^{5}$.

Como nosso objetivo é analisar as informações disponíveis na internet sobre todos os deputados estaduais, agruparemos os dados coletados por região e por tipo de partidos para facilitar a análise das informações, não excluindo nenhum deputado ou partido. Nesse sentido, com o intuito de tornar mais sistemática a apresentação dos dados efetuada a seguir, resolvemos classificar os partidos em seis grupos de agremiações relevantes, utilizando critérios um pouco diferentes dos adotados pela literatura que estuda o sistema partidário nacional (RODRIGUES, 2002; 2006) e que usualmente classifica os partidos em "esquerda" (PT, PCdoB etc.), “centro” (PSDB, PMDB) e “direita” (PFP, PP). Tal tipologia visa a inserir uma dimensão adicional nas análises tradicionais por espectro ideológico, na medida em que procura apreender também a natureza mais ou menos "fisiológica" do sistema partidário brasileiro, ou seja, o grau de coerência do comportamento dos partidos em relação a sucessivos governos na cena política nacional. Combinando esses dois critérios (posição no espectro ideológico e maior ou menor grau de fisiologismo ${ }^{-}$ou seja, de

\footnotetext{
5 Evidentemente, isso não deve ser confundido com a ausência de representação de partidos de esquerda nos legislativos estaduais, mas sim ser tomado como um indicador de que a estratégia mais comum adotada por "candidatos avulsos” para eleger-se nesses órgãos parlamentares é a filiação a pequenos partidos do centro e da direita do espectro ideológico. No tocante ao percentual relativo das correntes ideológicas nas assembléias e câmaras estaduais, elas são as seguintes, segundo os critérios por nós empregados: direita: 387 deputados (36,5\%); centro: 375 deputados (35,4\%); esquerda: 297 deputados (28,1\%).
}

adesismo aos sucessivos governos no plano nacional), podemos definir seis grandes grupos de partidos, que são os seguintes:

(1) partidos fisiológicos de centro (PFC): são aqueles que não se colocam em nenhum dos extremos do espectro político-ideológico e cuja postura em relação aos sucessivos governos no plano nacional é pouco coesa, oscilante ou difícil de caracterizar. Exemplos desses partidos são o PMDB e o PL;

(2) Como partidos fisiológicos de direita (PFD), por exemplo, classificaremos o PTB e o PP, além dos pequenos partidos de direita, agremiações que apresentam uma postura ideológica geral mais conservadora, mas que não são facilmente identificáveis com as linhas programáticas e as facções “anti” e prógoverno que polarizam o debate político, apresentando uma consistência programática menor em relação aos sucessivos governos na cena política nacional;

(3) partidos fisiológicos (ou populistas) de esquerda (PFE) são o PDT e o PSB, agremiações que se estruturam em torno de fortes lideranças estaduais e cujo comportamento "anti” e pró-governo não é facilmente identificável, aderindo ou fazendo oposição a governos de perfis programáticos distintos;

(4)partidos programáticos de direita (PPD) são aqueles partidos tradicionalmente incluídos no campo ideológico mais conservador e que apresentam uma postura ideológico-programática mais definida e consistente, sendo mais fácil de classificá-los em um gradiente "governo” versus “oposição”. Inserimos nessa rubrica o antigo PFL, embora a própria mudança de sigla em virtude de uma derrota nas urnas para DEM (Democratas) coloque problemas à sua caracterização como um partido "programático";

(5) partidos programáticos de centro (PPC) são o PSDB e o PPS;

(6) partidos programáticos de esquerda (PPE) são o PT, o PSOL, o PCdoB e o PV.

O objetivo dessa tipologia é tentar estabelecer uma classificação um pouco mais matizada que a tradicional, baseada no espectro ideológico ("esquerda”, “centro”, “direita”) empregada por di- 
versos outros analistas do sistema partidário nacional (FIGUEIREDO \& LIMONGI, 1999; RODRIGUES, 2006), inserindo uma dimensão adicional na análise do sistema partidário (natureza mais ou menos "fisiológica" dos partidos e dos seus deputados). Além disso, os objetivos dessa classificação são apenas facilitar a organização das informações apresentadas a seguir, bem como verificar se os dados coletados nos portais das assembléias legislativas permitem-nos ou não inferir eventuais diferenças nos perfis de recrutamentos dos vários tipos de partidos representados nas assembléias e com qual grau de intensidade.

Com relação às variáveis “brutas” que usamos para elaborar as planilhas prosopográficas, elas estão enumeradas na tabela abaixo, acompanhadas das freqüências de cada item encontradas nos portais nas 27 assembléias legislativas brasileiras pesquisadas.

\begin{tabular}{|c|c|}
\hline l) PERFIL SOC [AL DOS DEPUTADOS EST ADUAIS ([AT RIBUT OS INAT OS E ADQUIRIDOS) & $\%$ \\
\hline Foto do parlamentar & 869 \\
\hline Irformaçóes sobre local de nascimento & 56,3 \\
\hline Irformaçốes satisfatórias sobre escolaridade e curso superior & 548 \\
\hline Irformação sobre data de nas cimento & 44,2 \\
\hline informaçãa sobre estado chuil & 31,3 \\
\hline Irformaçốes satisfatórias sobre atividade profizsional & 290 \\
\hline Irforma nome dos pais & 21,0 \\
\hline Irforma profissâo dos pais & 4,4 \\
\hline Irformaçốes sobre escolaridade dos pais & 0,5 \\
\hline Irformaçốes sobre ano em que concluiu o último cusso & 0,3 \\
\hline \multicolumn{2}{|l|}{ II) T RAJET ÓRIA POLÍTICA } \\
\hline Irformaçôs sobre primeira atuvid ade formal exercida na política & 73,4 \\
\hline Irformaçós sobre local de entada na poítica & 69,7 \\
\hline Irforma primeiro mandato eletivo anterior & 62,1 \\
\hline Irformaçôs sobre votação do parlamentar & 568 \\
\hline Destaque para mandatos legislativos anteriores & 44,7 \\
\hline Irformaçôes sobre vínculos com movimentos associativos & 22,7 \\
\hline Irformaçós sobre metas ou plataformas eleitoras & 215 \\
\hline Destaque para filiaçôes partidárias arteriores & 195 \\
\hline Destaque para cargos administrativos anteriores (eletivos ou nâo) & 175 \\
\hline Irformaçôs sobre ativid ade intelectual & 3,9 \\
\hline \multicolumn{2}{|l|}{ IIIJ COMPORT AMENTO POLÍTICO A.PART IR DOS PERFIS } \\
\hline Tem email para contato & 749 \\
\hline Disponibiliza fone para contato & 68,7 \\
\hline Irforma endereço de gabinete & 54,3 \\
\hline Destaques para cargo ocupado na casa & 42,4 \\
\hline Lirk para pts a partir dos perfis & 33,7 \\
\hline Lirk para outras proposiçốes além de PLs & 26.1 \\
\hline Lirk para requerimentos & 218 \\
\hline Existência de néb site & 16,6 \\
\hline \multicolumn{2}{|l|}{ M) COMPORTAMENT O POLÍ ICO A.PARTIR DOS STES: } \\
\hline Cargos ocup ados a partir do site & 75,0 \\
\hline É possívelter acesso às proposiçốes apresentadas pelo parlamertar peb site & 52,4 \\
\hline Leis aprovadas a partir do site & 52,4 \\
\hline Irformaçôs agregadas sobre presença em plenário & 14,1 \\
\hline Irformaçôes agregadas sobre votação nominal & 14,1 \\
\hline Resultados ele itoraishotação do parlamentar a partir do site & 13,0 \\
\hline Irformaçôes sobre emendas or çamentárias a partir do site & 8,0 \\
\hline Presença nas Comissốes a partir do site & 5,2 \\
\hline
\end{tabular}

FONTE: Braga (2007b).

6 Quando damos “destaque para” determinada informação, isso significa que criamos um item específico, no perfil 
Na tabela acima apresentamos algumas das principais categorias brutas que constam da planilha elaborada, assim como a freqüência de parlamentares de quem conseguimos obter informações sobre essas variáveis. A partir delas, construímos as tabelas e elaboramos os indicadores que seguem abaixo.

\section{PERFIL SOCIAL E BIOGRÁFICO DOS DE- PUTADOS ESTADUAIS BRASILEIROS E A $W E B$}

Podemos agora, a partir dos dados brutos e agregados sintetizados na tabela anterior, efetuar uma análise do perfil social e da trajetória política pregressa dos 1059 deputados estaduais e distritais brasileiros. Frise-se que todas as categorias incluídas nas tabelas abaixo foram obtidas a partir dos dados brutos coletados nos portais das casas legislativas e resumidas na tabela anterior.

A primeira característica do perfil social dos parlamentares que analisaremos, assim como de sua presença na internet, são os "atributos inatos”, ou seja, aqueles que independem dos pro- cessos de socialização e de adaptação diferenciais dos quais foram objetos e agentes os próprios deputados a partir da data de seu nascimento. Com efeito, pelas informações contidas nestas tabelas podemos observar que ainda são bastante insatisfatórios os dados sobre os "atributos naturais” dos deputados estaduais brasileiros nos portais das assembléias. Se, por um lado, um total de $920(86,9 \%)$ dos parlamentares apresentam fotos de si mesmos nos portais, possibilitando assim a identificação da cor da pele a partir do exame visual de tais documentos, apenas 221 (21,0\%) mencionam o nome de pelo menos um de seus pais, $47(4,7 \%)$ informam as atividades profissionais dos pais e apenas cinco $(0,5 \%)$ esclarecem a escolaridade dos pais, o que prejudica enormemente a caracterização de eventuais processos de mobilidade social ocorridos entre gerações.

Não obstante a escassez de alguns dados, a partir dessas informações brutas podemos derivar as seguintes freqüências agregadas sobre o perfil social dos parlamentares:

TABELA 3 - PERFIL SOCIAL DOS DEPUTADOS A PARTIR DA WEB (ATRIBUTOS NATURAIS E REGIÃO)

\begin{tabular}{|c|c|c|c|c|c|c|c|c|c|c|c|c|}
\hline & \multicolumn{2}{|c|}{$\begin{array}{c}\text { CENTRO- } \\
\text { OESTE }\end{array}$} & \multicolumn{2}{|c|}{ NORDESTE } & \multicolumn{2}{|c|}{ NORTE } & \multicolumn{2}{|c|}{ SUDESTE } & \multicolumn{2}{|c|}{ SUL } & \multicolumn{2}{|c|}{ TOTAL } \\
\hline & $N$ & $\%$ & $N$. & $\%$ & $N$. & $\%$ & $N$. & $\%$ & $N$. & $\%$ & $N$ & $\%$ \\
\hline \multicolumn{13}{|l|}{ Fotografia } \\
\hline Parlamentares sem foto & 3 & 2,7 & 35 & 10,3 & 76 & 41,1 & 23 & 8,5 & 2 & 1,3 & 139 & 13,1 \\
\hline Parlamentares com foto & 110 & 97,3 & 306 & 89,7 & 109 & 58,9 & 248 & 91,5 & 147 & 98,7 & 920 & 86,9 \\
\hline $\begin{array}{l}\text { Total } \\
\text { Cor da pele dos deputados }\end{array}$ & \multicolumn{11}{|c|}{ Cor da pele dos deputados } & 100,0 \\
\hline Branca & 94 & 74,6 & 247 & 67.7 & 8 & 67.7 & 211 & 74,0 & 129 & 782 & 769 & 71,8 \\
\hline Negra & 1 & 0,8 & 11 & 30 & 2 & 1,5 & 8 & 2,8 & 2 & 1,2 & 24 & 2,2 \\
\hline Parda & 15 & 11,9 & 48 & 13,2 & 19 & 14,6 & 29 & 10,2 & 16 & 9.7 & 127 & 11.9 \\
\hline Negos e pardos & 16 & 12,7 & 59 & 16,2 & 21 & 16,2 & 37 & 13,0 & 18 & 109 & 151 & 14,1 \\
\hline $\begin{array}{l}\text { Total } \\
\text { Faixa etária }\end{array}$ & 110 & 100 & 306 & 100 & 109 & 100 & 248 & 100 & 147 & 100 & 920 & 100 \\
\hline 20 a 30 & 2 & 3,4 & 9 & 6,0 & 1 & 2,6 & 8 & 6.6 & 5 & 4,8 & 25 & 5,3 \\
\hline 31 a 40 & 16 & 27,6 & 33 & 22,0 & 11 & 28,2 & 22 & 18,0 & 18 & 17,3 & 100 & 21,1 \\
\hline 41 a 50 & 26 & 44,8 & 57 & $\$, 0$ & 18 & 46,2 & 46 & 37.7 & 45 & 43,3 & 192 & 40,6 \\
\hline 51 a 60 & 13 & 22,4 & 40 & 26,7 & 8 & 20,5 & 40 & 32,8 & 28 & 269 & 129 & 27,3 \\
\hline Mais de 61 & 1 & 1.7 & 11 & 73 & 1 & 2,6 & 6 & 4,9 & 8 & 7.7 & 27 & 5.7 \\
\hline Total & 58 & 100,0 & 150 & 1000 & 39 & 1000 & 122 & 100,0 & 104 & 100,0 & 473 & 100,0 \\
\hline \multicolumn{13}{|l|}{ Sexo } \\
\hline Feminino & 17 & 15,0 & 42 & 12,3 & 22 & 11,9 & 39 & 14,4 & 10 & 6,7 & 130 & 12,3 \\
\hline Masculino & 96 & 85,0 & 299 & 87,7 & 163 & 88,1 & 232 & 85,6 & 139 & 933 & 929 & 87.7 \\
\hline $\begin{array}{l}\text { Total } \\
\text { Índice de localis mo }\end{array}$ & 113 & 100,0 & 341 & 1000 & 185 & 1000 & 271 & 100,0 & 149 & 100,0 & 1069 & 100,0 \\
\hline Nasceram no mesmo estado & 50 & 50,0 & 142 & 84,5 & 20 & $\$, 1$ & 127 & 7,0 & 86 & 81,1 & 425 & 71,3 \\
\hline Nasceram em outro estado & 50 & 50,0 & 26 & 15,5 & 37 & 64,9 & 38 & 23,0 & 20 & 189 & 171 & 28,7 \\
\hline Total & 100 & 100,0 & 168 & 1000 & 57 & 100,0 & 165 & 100,0 & 106 & 100,0 & 596 & 100,0 \\
\hline
\end{tabular}

FONTE: Braga (2007b).

de cada parlamentar, para indicar a existência de tal informação, não estando ela misturada a outros dados sobre os deputados no corpo de seu perfil. Um bom exemplo desse tipo de organização das informações sobre os parlamentares pode ser encontrado no portal da Câmara dos Deputados e de algumas assembléias estaduais brasileiras, como as da Bahia, de Goiás e de Minas Gerais. 
Embora não possam ser tomados como significativos de toda a população observada, os dados obtidos permitem-nos chegar a algumas conclusões interessantes, especialmente sobre gênero, cor da pele e "índice de localismo" - todas essas dimensões são relevantes para a caracterização dos perfis de recrutamento dos legislativos estaduais brasileiros. Assim, observamos que os estados da região Sul apresentam o maior percentual de parlamentares com fotografia disponível na internet, menor contingente de negros e pardos, e menor contingente de deputadas - um dado que pode ser considerado surpreendente pois, via de regra, são os estados das regiões Norte e Nordeste que costumam ficar com a pecha de "machistas" e portadores de uma cultura patriarcal. Por outro lado, também como esperado, são os estados das regiões Norte e Centro-Oeste que apresentam menor grau de localismo, sendo os membros das elites parlamentares desses estados predominantemente migrantes.

No tocante aos tipos de partidos, os dados mais relevantes que obtivemos da coleta foram os seguintes:

TABELA 4 - PERFIL SOCIAL DOS DEPUTADOS A PARTIR DA WEB (ATRIBUTOS NATURAIS E TIPOS DE PARTIDO)

\begin{tabular}{|c|c|c|c|c|c|c|c|c|c|c|c|c|c|c|}
\hline & \multicolumn{2}{|c|}{ PFC } & \multicolumn{2}{|c|}{ PFD } & \multicolumn{2}{|c|}{ PFE } & \multicolumn{2}{|c|}{ PPC } & \multicolumn{2}{|c|}{ PPD } & \multicolumn{2}{|c|}{ PPE } & \multicolumn{2}{|c|}{ TOTAL } \\
\hline & N. & 㽞 & N. & $\%$ & N. & 吆 & N. & \% & N. & 吅 & N. & 吻 & N. & 吆 \\
\hline \multicolumn{15}{|c|}{ Fotografia do deputado } \\
\hline $\begin{array}{l}\text { arlamentares sem } \\
\text { oto }\end{array}$ & 26 & 13,3 & 44 & 19,3 & 19 & 15,1 & 221 & 10,6 & 14 & 10,9 & 14 & 8,1 & 139 & 13,1 \\
\hline $\begin{array}{l}\text { arlamentares com } \\
\text { tho }\end{array}$ & 169 & 86,7 & 184 & 80,7 & 107 & 84,9 & 186 & 89,4 & 115 & 89,1 & 159 & 91,9 & 920 & 86,9 \\
\hline 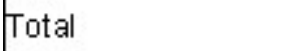 & 195 & 100,0 & 228 & 100,0 & 126 & 100,0 & 208 & 100,0 & 129 & 100,0 & 173 & 100,0 & 1059 & 100,0 \\
\hline \multicolumn{15}{|c|}{ Cor da pele dos deputados } \\
\hline tran & 140 & 70,7 & 149 & 68,0 & 94 & 78,3 & 165 & 79,7 & 97 & 72,9 & 124 & 63,9 & 769 & 72,6 \\
\hline & & & 6 & & & & 2 & & & 0,8 & & 4,1 & & 2,3 \\
\hline & 24 & 12,1 & 29 & 13,2 & 11 & 9,2 & 19 & 9,2 & 17 & 12,8 & 27 & 13,9 & 127 & 12,0 \\
\hline 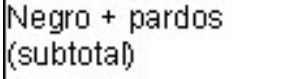 & 29 & 14,6 & 35 & 16,0 & 13 & 10,8 & 21 & 10,1 & 18 & 13,5 & 35 & 18,0 & 151 & 14,3 \\
\hline & 169 & 100 & 84 & 100 & 107 & 100 & 186 & 100 & 115 & 100 & 159 & 100 & 920 & 86,9 \\
\hline \multicolumn{15}{|c|}{ F aixa etária por região } \\
\hline 20 a 30 & 5 & & & & 3 & 6,0 & 6 & 7,0 & & & & 2,6 & 25 & 5,3 \\
\hline & & 21,4 & 22 & 23,9 & 8 & 16,0 & 20 & 23,3 & & 10,8 & 21 & 27,3 & 100 & 21,1 \\
\hline & 27 & 26,2 & 26 & 28,3 & 11 & 22,0 & 26 & 30,2 & 12 & 18,5 & 23 & 29,9 & 125 & 26,4 \\
\hline & 5 & 54,4 & & 34,8 & 9 & 38,0 & 32 & 37,2 & 9 & 29,2 & 34 & 44,2 & 192 & 40,6 \\
\hline & 1 & 16,5 & 2 & 29,3 & 18 & 36,0 & 25 & 29,1 & & & 17 & 22,1 & 129 & 27,3 \\
\hline & 3 & 2,9 & & 7,6 & 2 & 4,0 & 3 & 3,5 & 9 & 13,8 & 3 & 3,9 & 27 & 5,7 \\
\hline Total & 103 & 100 & 92 & 100 & 50 & 100 & 86 & 100 & 65 & 100 & 77 & 100 & 473 & 100 \\
\hline \multicolumn{15}{|l|}{ Gênero } \\
\hline & 2 & 13,8 & & & 7 & 13,5 & 26 & 12,5 & 0 & 7,8 & 29 & 16,8 & 130 & 12,3 \\
\hline & & 86,2 & 207 & 90,8 & 109 & 86,5 & 182 & 87,5 & 119 & 92,2 & 144 & 83,2 & 929 & 87,7 \\
\hline Total & 195 & 100,0 & 228 & 100,0 & 126 & 100,0 & 208 & 100,0 & 129 & 100,0 & 173 & 100,0 & 1059 & 100,0 \\
\hline \multicolumn{15}{|c|}{ Índice de localismo } \\
\hline & 85 & 66,9 & 94 & 73,4 & 39 & 69,6 & 84 & 71,8 & 55 & 70,5 & 68 & 75,6 & 425 & 71,3 \\
\hline Nasc & 42 & 33,1 & 34 & 26,6 & 17 & 30,4 & 33 & 28,2 & 23 & 29,5 & 22 & 24,4 & 171 & 28,7 \\
\hline Total & 127 & 100,0 & 128 & 100,0 & 56 & 100,0 & 117 & 100,0 & 78 & 100,0 & 90 & 100,0 & 596 & 100,0 \\
\hline
\end{tabular}

FONTE: Braga (2007b). 
Apesar de os dados coletados a partir dos websites não abrangerem a população como um todo, podemos chegar a algumas conclusões interessantes a partir do exame da tabela acima. Podemos notar que aquelas agremiações que denominamos de "partidos programáticos de esquerda” (PPE) apresentam um percentual mais elevado em algumas dimensões de seu recrutamento, que os colocam em uma posição simétrica vis-àvis outros tipos de agremiação, especialmente os PFD e PPC. Assim, enquanto os PPE apresentam um percentual mais elevado de deputados que apresentam fotos na internet (91,9\%), de cor da pele negra ou parda $(18,0 \%)$, de faixa etária abaixo dos 40 anos (29,9\%), maior percentual de mulheres em suas fileiras $(16,8 \%)$ e parlamentares que nasceram no mesmo estado em que foram eleitos (75,6\%), os PFD e PPC apresentaram percentuais mais reduzidos em relação a itens como disponibilidade de fotografia dos parlamentares (PFD: 80,7\%), cor da pele dos deputados (PPD: 10,1\% de deputados negros e pardos), presença de mulheres nas bancadas (PFD: 9,2\%) e deputados originários de estados onde existe maior grau de imigração (PFC: 33,1\%). Assim, algumas diferenças específicas em relação às características da composição das diferentes agremiações que compõem os legislativos esta- duais brasileiros já podem ser visualizadas a partir dos dados disponíveis nos portais das casas legislativas.

Uma vez caracterizados os atributos "inatos" disponíveis na internet sobre os deputados estaduais brasileiros na última legislatura, podemos avançar na análise do grau de presença dos atributos "adquiridos" ou "conquistados" por tais elites parlamentares em seu processo de socialização.

Pelos dados contidos no Anexo 2, podemos avaliar a disponibilidade global das informações sobre os "atributos adquiridos" do perfil social dos parlamentares contida nos portais das assembléias examinados. Assim, dos 1059 deputados, apenas $331(31,3 \%)$ apresentam informações satisfatórias que permitem definir seu estado civil; 580 (54,8\%) sobre os níveis de escolaridade; 234 (22,1\%) sobre a instituição em que efetuou a formação escolar; três $(0,3 \%)$ sobre o ano em que se formou ou concluiu a formação escolar e 307 (29,0\%) apresentam “informações satisfatórias” sobre o exercício da profissão ${ }^{7}$. Entretanto, mesmo insatisfatórios de uma perspectiva mais ampla, os dados contidos nos portais das assembléias permitem-nos chegar aos seguintes resultados sobre o perfil regional e partidário dos deputados:

TABELA 5 - PERFIL SOCIAL DOS DEPUTADOS A PARTIR DA WEB (CARACTERÍSTICAS ADQUIRIDAS E REGIÕES)

\begin{tabular}{|c|c|c|c|c|c|c|c|c|c|c|c|c|}
\hline & \multicolumn{2}{|c|}{$\begin{array}{l}\text { CENTRO- } \\
\text { OESTE }\end{array}$} & \multicolumn{2}{|c|}{ NORDESTE } & \multicolumn{2}{|c|}{ NORTE } & \multicolumn{2}{|c|}{ SUDESTE } & \multicolumn{2}{|c|}{ SUL } & \multicolumn{2}{|c|}{ TOTAL } \\
\hline & $N$ & $\%$ & $N$ & 吸 & N. & 吸 & $N$ & 吆 & $N$ & $\%$ & $N$ & 吸 \\
\hline \multicolumn{13}{|l|}{ Estado civil } \\
\hline Casado & 58 & 95,1 & 139 & 97,9 & 52 & 94,5 & 14 & 100,0 & 55 & 93,2 & 318 & 96,1 \\
\hline Solteiro & 1 & 1,6 & 2 & 1,4 & 3 & 5,5 & 0 & 0,0 & 4 & 6,8 & 10 & 3,0 \\
\hline Divorciado & 2 & 3,3 & 1 & 0,7 & 0 & 0,0 & 0 & 0,0 & 0 & 0,0 & 3 & 0,9 \\
\hline Total & 61 & 100,0 & 142 & 100,0 & 55 & 100,0 & 14 & 100,0 & 59 & 100,0 & 331 & 100,0 \\
\hline \multicolumn{13}{|l|}{ Escolaridade agregada } \\
\hline Superior & 56 & 84,8 & 177 & 87,6 & 29 & 78,4 & 152 & 93,8 & 83 & 73,5 & 497 & 85,7 \\
\hline Superior incompleto & 6 & 9,1 & 3 & 1,5 & 4 & 10,8 & 6 & 3,7 & 9 & 8,0 & 28 & 4,8 \\
\hline Ensino Médio & 3 & 4,5 & 18 & 8,9 & 4 & 10,8 & 4 & 2,5 & 17 & 15,0 & 46 & 7,9 \\
\hline Ensino Fundamental & 1 & 1,5 & 4 & 2,0 & 0 & 0,0 & 0 & 0,0 & 4 & 3,5 & 9 & 1,6 \\
\hline (Não Superior) [Sub-Total] & 4 & 6,1 & 22 & 10,9 & 4 & 10,8 & 4 & 2,5 & 21 & 18,6 & 55 & 9,5 \\
\hline Total & 66 & 100,0 & 202 & 100,0 & 37 & 100,0 & 162 & 100,0 & 113 & 100,0 & 580 & 100,0 \\
\hline \multicolumn{13}{|l|}{ Profissão/desagregada } \\
\hline Proprietários ou empresários & 22 & 24,7 & 35 & 15,0 & 19 & 18,3 & 43 & 20,7 & 30 & 23,6 & 149 & 19,6 \\
\hline
\end{tabular}

7 “Informações satisfatórias” são aquelas que nos permitem preencher a maior parte (não todos, o que seria exigir demais no atual estágio de informatização dos portais das assembléias) dos itens da planilha prosopográfica que elaboramos para estudar os deputados da $15^{\mathrm{a}}$ Legislatura. 


\begin{tabular}{|c|c|c|c|c|c|c|c|c|c|c|c|}
\hline \multicolumn{12}{|l|}{ Profissão/desagregada } \\
\hline Proprietários ou empresários & 22 & 24,7 & 35 & 15,0 & 19 & 18,3 & 43 & 20,7 & 30 & $23,6 \quad 149$ & 19,6 \\
\hline Intelectuais/ C. Sociais Aplicadas & 16 & 18,0 & 75 & 32,1 & 18 & 17,3 & 41 & 19,7 & 21 & $16,5 \quad 171$ & 22,4 \\
\hline Intelectuais/ C. Biológicas-Saúde & 7 & 7,9 & 42 & 17,9 & 20 & 19,2 & 30 & 14,4 & 7 & $5,5 \quad 106$ & 13,9 \\
\hline Intelectuais/ C. Humanas & 12 & 13,5 & 28 & 12,0 & 13 & 12,5 & 37 & 17,8 & 15 & $11,8 \quad 105$ & 13,8 \\
\hline Intelectuais/ C. Exatas & 15 & 16,9 & 19 & 8,1 & 14 & 13,5 & 15 & 7,2 & 11 & $8,7 \quad 74$ & 9,7 \\
\hline Assalariado sem nível superior & 16 & 18,0 & 29 & 12,4 & 17 & 16,3 & 36 & 17,3 & 28 & $22,0 \quad 126$ & 16,5 \\
\hline Estudante & 0 & 0,0 & 4 & 1,7 & 0 & 0,0 & 1 & 0,5 & 2 & $1,6 \quad 7$ & 0,9 \\
\hline Braçal & 1 & 1,1 & 2 & 0,9 & 3 & 2,9 & 5 & 2,4 & 13 & $10,2 \quad 24$ & 3,1 \\
\hline Total & 89 & 100,0 & 234 & 100,0 & 104 & 100,0 & 208 & 100,0 & 127 & 100,0762 & 100,0 \\
\hline \multicolumn{12}{|l|}{ Profissão agregada } \\
\hline ProprietáriosiEmpresários & 22 & 24,7 & 35 & 15,0 & 19 & 18,3 & 43 & 20,7 & 30 & $23,6 \quad 149$ & 19,6 \\
\hline Intelectuais de Alta Escolaridade & 50 & 56,2 & 168 & 71,8 & 65 & 62,5 & 124 & 59,6 & 56 & $44,1 \quad 463$ & 60,8 \\
\hline $\begin{array}{l}\text { Intelectuais de Baixa } \\
\text { Especializaçẫo }\end{array}$ & 16 & 18,0 & 29 & 12,4 & 17 & 16,3 & 36 & 17,3 & 28 & $22,0 \quad 126$ & 16,5 \\
\hline Trabalh & 1 & 1,1 & 2 & 0,9 & 3 & 2,9 & 5 & 2,4 & 13 & $10,2 \quad 24$ & 3,1 \\
\hline Total & 89 & 100,0 & 234 & 100,0 & 104 & 100,0 & 208 & 100,0 & 127 & 100,0762 & 100,0 \\
\hline
\end{tabular}

FONTE: Braga (2007b).

Dos 1059 deputados estaduais brasileiros, apenas 331 apresentam informações sobre seu estado civil, o que podemos considerar um índice bastante baixo. Entretanto, o dado mais interessante da tabela é a recusa generalizada, em todas as regiões do país (assim como em todos os partidos, como veremos adiante) de os políticos declararem-se solteiros ou divorciados. Apenas 13 $(3,9 \%)$ do total de 331 parlamentares que declararam seu estado civil informaram ser "solteiros" ou "divorciados". Podemos aventar diversas hipóteses para tal silêncio e que podem mesmo ser objeto de estudos em outra oportunidade. O que importa aqui é caracterizar a existência de tal fenômeno, parecendo indicar que a manutenção de uma família nuclear estável e coesa (ou, ao menos, a aparência da manutenção desse status social) é um capital político valorizado pelos deputados e, também, pelo eleitorado ${ }^{8}$.

No tocante aos dados sobre "escolaridade agregada”, deparamo-nos com um fenômeno de natureza análoga, o que nos permite ao menos formular a hipótese da existência de um excesso de

\footnotetext{
8 Os dados obtidos sobre o estado civil de todos os 1059 deputados estaduais eleitos no pleito de 2002 na planilha Access disponível no portal do TSE são os seguintes: casados: 74,3\%; solteiros: 13,5\%; divorciados: 5,1\%; viúvos: 1,6\%; não informados: $1,1 \%$. Isso reforça a percepção a respeito de um cálculo político dos deputados na apresentação de tais informações na internet, muito mais que um apego excessivo à privacidade.
}

sensibilidade dos parlamentares a determinados valores preconceituosos que ainda permeiam a sociedade brasileira. Assim, dos 580 parlamentares que informaram sua escolaridade, apenas 55 (9,5\%) fizeram-no para cursos não-universitários. Sintomaticamente, foi na região Sudeste, onde existem estados habitados com maior contingente populacional de classe média portadora de valores meritocráticos mais conservadores, que ocorreu a menor freqüência de deputados que "declararam", por meio de seus perfis, possuir apenas Ensino Fundamental ou Médio, como se tal condição fosse um estigma incompatível com o exercício da atividade política ${ }^{9}$.

Em relação aos dados por profissão, podemos observar também que eles seguem a seqüência clássica de Direito (14,3\%), Medicina (6,8\%) e Engenharia (6,8\%). Deve-se destacar, no entanto, o elevado percentual de disciplinas "emergentes” da área de Ciências Sociais Aplicadas, como Administração de Empresas (6,8\%), Economia $(4,6 \%)$ e Contabilidade (1,4\%), revelando ainda um padrão mais diversificado na formação da classe política brasileira, tradicionalmente sob o domínio dos "bacharéis".

9 Os dados do TSE para os eleitos de 2002 são os seguintes: Nível Superior completo: 61,9\%; Nível Superior incompleto: 13,2\%; Ensino Médio (completo e incompleto): 17,3\%; Ensino Fundamental (completo e incompleto): 5,8\%; lê e escreve: 0,5\%; não informado: 1,3\%. 
No tocante ao exercício de atividades profissionais, optamos por agregar os dados a partir de dois critérios, pois, com as informações que obtivemos, haveria pouco rendimento analítico em sua organização discriminando-se o setor "público" ou "privado" de exercício da profissão pelo ator examinado. Assim, optamos por agregá-las a partir de um duplo critério, mais compatível com as informações obtidas em nossa pesquisa: a) conforme a área de especialização revelada pela escolaridade do Deputado, exceto nos casos de proprietários ou empresários, trabalhadores braçais e assalariados sem curso superior; b) segundo o grau de especialização ou nível de escolaridade necessário ao exercício da profissão pelos atores examinados.

Empregando os critérios acima e excluindo os atores para os quais não obtivemos informações, devemos destacar alguns aspectos: a) o baixo contingente de parlamentares que informaram em seus perfis serem proprietários ou “empresários”; b) o predomínio das profissões intelectuais no recrutamento das assembléias, especialmente originários das áreas de Ciências Sociais Aplicadas; c) a baixa proporção de profissões menos qualificadas e de trabalhadores manuais entre os deputados estaduais, apresentando pouca variação em relação aos padrões de recrutamento observados em outros órgãos parlamentares (MARENCO, 2000, p. 84).

No que se refere aos "atributos conquistados" do perfil social dos deputados estaduais por "tipos de partido”, os dados são os que seguem abaixo:

TABELA 6 - PERFIL SOCIAL DOS DEPUTADOS A PARTIR DA WEB (CARACTERÍSTICAS ADQUIRIDAS E TIPOS DE PARTIDO)

\begin{tabular}{|c|c|c|c|c|c|c|c|c|c|c|c|c|c|c|}
\hline \multirow{2}{*}{ Escolaridade agegada } & \multicolumn{2}{|c|}{$\mathrm{PFC}$} & \multicolumn{2}{|c|}{ PFD } & \multicolumn{2}{|c|}{ PFE } & \multicolumn{2}{|c|}{$\mathrm{PPC}$} & \multicolumn{2}{|c|}{ PPD } & \multicolumn{2}{|c|}{ PPE } & \multicolumn{2}{|c|}{ TOTAL } \\
\hline & & & & & & & & & & & & & & \\
\hline Ensino Fund amental & 1 & 0,8 & 3 & 2,7 & 1 & 1,9 & 2 & 1,8 & 0 & 0,0 & 2 & 18 & 9 & 1,6 \\
\hline Ensino Médio & 7 & 5,9 & 15 & 13,5 & 6 & 115 & 6 & 5,4 & 5 & 6,4 & 7 & 6,4 & 46 & 7,9 \\
\hline Superior Incompleto & 6 & 5,1 & 6 & 5,4 & 3 & 5,8 & 7 & 6,3 & 0 & 0,0 & 6 & 55 & 28 & 4,8 \\
\hline Superior & 104 & 88,1 & 87 & 78.4 & 42 & 808 & 97 & 86,6 & 73 & 93,6 & 94 & 86,2 & 497 & 85,7 \\
\hline Total & 118 & 100 & 111 & 100 & 52 & 100 & 112 & 100 & 78 & 100 & 109 & 100 & 580 & 100 \\
\hline \multicolumn{15}{|l|}{ Profissక̄o desagregada } \\
\hline Prop rietários ou empresários & 25 & 17,1 & 40 & 26,3 & 18 & 23,7 & 40 & 26,3 & 24 & 23,5 & 2 & 15 & 149 & 19,6 \\
\hline Intelectuais/C. Sociais Aplicadas & 34 & 23,3 & 32 & 21,1 & 11 & 145 & 40 & 26,3 & 31 & 30,4 & 23 & 17,2 & 171 & 22,4 \\
\hline Intelectuais/C. Bióógicas-Saúde & 19 & 130 & 20 & 13.2 & 11 & 145 & 23 & 15,1 & 17 & 16,7 & 16 & 11,9 & 106 & 13,9 \\
\hline Intelectuais/C. Humanas & 21 & 14,4 & 13 & 8,6 & 7 & 9,2 & 16 & 10,5 & 7 & 6,9 & 41 & 30,6 & 105 & 13,8 \\
\hline Intelectuais/C. Exatas & 18 & 123 & 10 & 6,6 & 5 & 6.6 & 15 & 9,9 & 10 & 9,8 & 16 & 11,9 & 74 & 9,7 \\
\hline Assalariado sem nímelsuperior & 25 & 17,1 & 31 & 20.4 & 19 & 250 & 17 & 11,2 & 11 & 10,8 & 23 & 17,2 & 126 & 16,5 \\
\hline Estud ante & 2 & 1,4 & 0 & 0,0 & 3 & 3,9 & 0 & 0,0 & 0 & 0,0 & 2 & 15 & 7 & 0,9 \\
\hline Braçal & 2 & 1.4 & 6 & 3,9 & 2 & 2,6 & 1 & 0,7 & 2 & 2,0 & 11 & 82 & 24 & 3,1 \\
\hline Total & 146 & 100 & 152 & 100 & 76 & 100 & 152 & 100 & 102 & 100 & 134 & 100 & 762 & 100 \\
\hline \multicolumn{15}{|l|}{ Profissões por gruposkgregado } \\
\hline Prop rietários ou empresários & 25 & 17,1 & 40 & 26,3 & 18 & 23,7 & 40 & 26,3 & 24 & 23,5 & 2 & 15 & 149 & 19,6 \\
\hline Intelectuais de alta escolaridade & 94 & 64,4 & 75 & 49,3 & 37 & 48,7 & 94 & 61.8 & 65 & 63.7 & 98 & 73,1 & 463 & 60.8 \\
\hline Intelectuais de baixa especialização & 25 & 17,1 & 31 & 20.4 & 19 & 250 & 17 & 11,2 & 11 & 10.8 & 23 & 17,2 & 126 & 16,5 \\
\hline Trabalhadores braçais & 2 & 1.4 & 6 & 3,9 & 2 & 2,6 & 1 & 0,7 & 2 & 2,0 & 11 & 8,2 & 24 & 3,1 \\
\hline Total & 145 & 100 & 152 & 100 & 76 & 100 & 152 & 100 & 102 & 100 & 134 & 100 & 762 & 100 \\
\hline
\end{tabular}

FONTE: Braga (2007b).

Os percentuais acima corroboram a proposição anterior acerca da tendência de todos os partidos políticos de omitirem informações sobre os níveis inferiores de escolaridade. Outro ponto a destacar é que, embora não obtivéssemos informações satisfatórias sobre a natureza estatal ou não-estatal da carreira profissional dos deputados estaduais, os percentuais da tabela fornecem indícios que nos permitem confirmar o fenômeno já observado por outros estudos em nível nacional acerca da existência de uma certa correlação entre padrão de estratificação social e características dos recrutamentos dos diferentes blocos partidários, embora as diferenças expostas na tabela acima sejam menos intensas do que as encontradas em outros estudos (MARENCO, 2000; RODRIGUES, 2006). Assim, partidos de esquerda, especialmente os mais "programáticos", apresentam percentuais mais elevados de profissões intelectuais (destacando-se os com formação universitária da área de Ciências Humanas) e trabalhadores braçais, enquanto partidos de direita e 
centro-direita tendem a ocupar uma posição simetricamente inversa.

Do ponto de vista da proposta inicial deste texto, no entanto, mais importante do que efetuar uma análise e descrição dos dados coletados é empreender uma avaliação do grau de disponibilidade das informações sobre as elites parlamentares nas casas legislativas que nos possibilite, entre outras coisas, um estudo sistemático de cunho prosoprográfico sobre tais atores. Tal proposta de avaliação e monitoramento de tais infor- mações consubstancia-se na elaboração de um "indicador" para avaliar o "grau de transparência" e de disponibilidade de tais informações nas casas legislativas. Tal indicador está corporificado no gráfico abaixo, que busca mensurar e hierarquizar a magnitude das informações sobre os deputados disponíveis nos portais legislativos brasileiros. $\mathrm{O}$ índice foi obtido a partir das médias ponderadas dos percentuais de presença das variáveis examinadas a partir de seu grau de relevância para nossa pesquisa ${ }^{10}$.

\section{GRÁFICO 1 - INFORMAÇÕES SOBRE PERFIL SOCIAL NOS PORTAIS DAS ASSEMBLÉIAS LEGISLATIVAS (MÉDIA PONDERADA DOS PERCENTUAIS)}

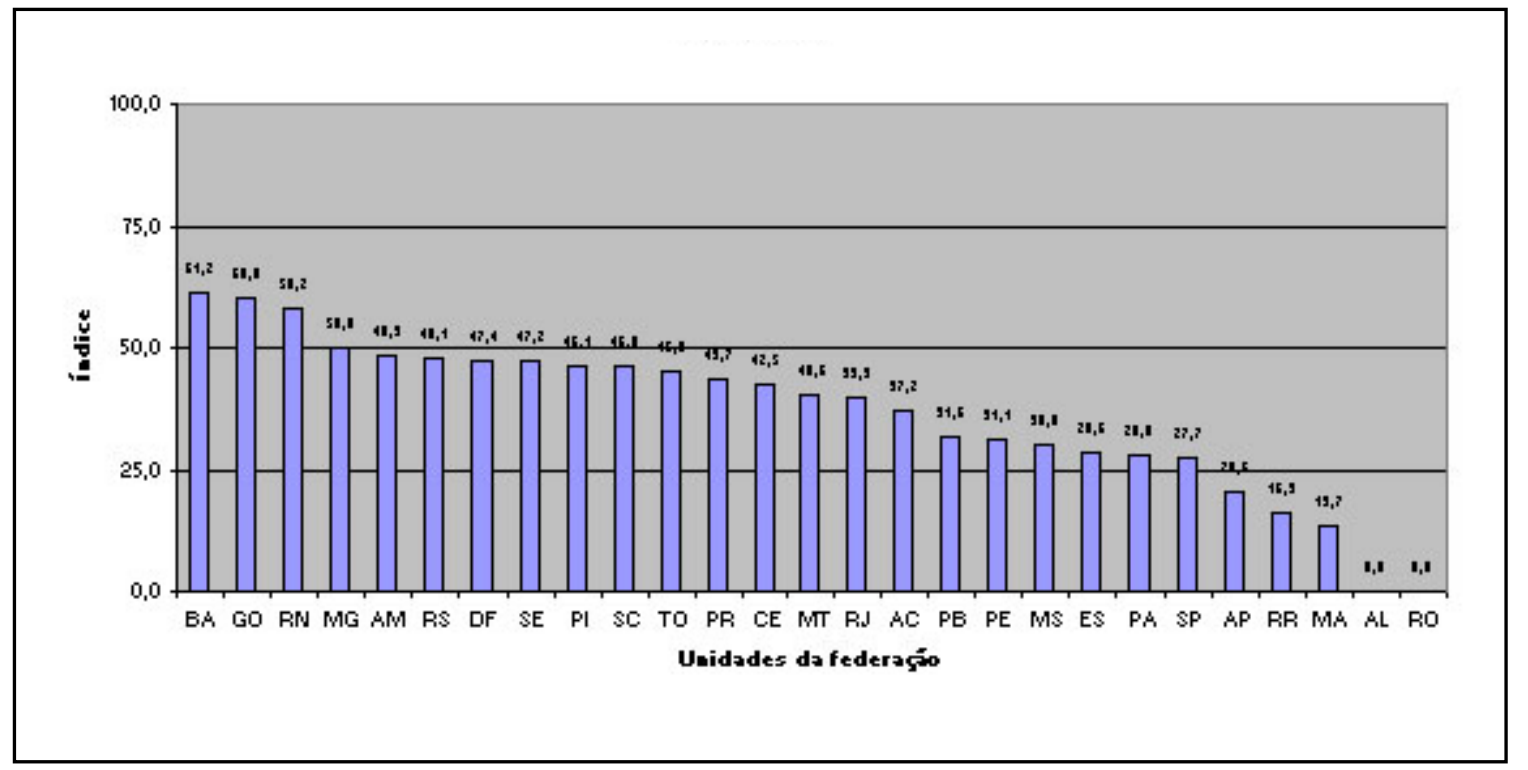

Pelo gráfico podemos observar que apenas quatro casas legislativas apresentam um grau de transparência satisfatório, ou seja, acima de média no tocante à disponibilização de informações sobre os atributos inatos e adquiridos de suas elites parlamentares (Bahia, Goiás, Rio Grande do Norte e Minas Gerais). Todos os demais portais apresentam informações insatisfatórias sobre o "perfil social” dos deputados. Não por acaso, os quatro sites que apresentaram melhor desempenho são justamente aqueles que adotam formulários-padrão para a apresentação de informações básicas sobre seus deputados, seguindo o exemplo da Câmara dos Deputados. Devido a isso, as informações básicas sobre os atributos inatos e adquiridos dos parlamentares são facilmente acessíveis a qualquer cidadão-internauta, mesmo quando os portais de algumas dessas assembléias não apresentem um elevado grau de sofisticação, como procuramos demonstrar em outro estudo (BRAGA, 2007b).

\section{TRAJETÓRIA E SOCIALIZAÇÃO POLÍTI- CADOS DEPUTADOS ESTADUAIS}

Nesta seção procuraremos avaliar o grau de presença de informações sobre a trajetória ou socialização política pregressa dos deputados. Nos estudos sobre recrutamento, via de regra a categoria de "socialização política” é empregada para designar itens relacionados à atividade política dos parlamentares antes do exercício do mandato parlamentar. A importância de dados sobre a trajetó-

10 Para um detalhamento da metodologia e dos critérios de ponderação das variáveis "fortes" e "fracas" que usamos na composição do índice, ver a planilha do Anexo 2. 
ria política para a compreensão da atividade das diferentes agremiações partidárias é particularmente destacada em estudos recentes, que afirmam que padrões de recrutamento mais endógenos e em segmentos sociais com menor patrimônio acumulado tendem a gerar partidos mais coesos e voltados à defesa dos interesses das classes trabalhadoras na arena política e parlamentar (MARENCO, 2000; MARENCO \& SERNA, 2007).

No tocante a informações sobre a trajetória política dos deputados estaduais, por meio do exame da freqüência desagregada dos itens mais importantes que constituíram nossa planilha prosopográfica, podemos observar que é bastante desigual o percentual de informações sobre as diversas variáveis pesquisadas.

Pelos dados da planilha anexa, podemos perceber que apenas 457 deputados (43,2\%) apresentam em seus perfis dados sobre a votação que os conduziu às assembléias; $32,8 \%$ sobre a data exata (ano) de sua primeira atividade política, excetuando o atual mandato de deputado estadual; apenas 17,5\% dão "destaque" (no sentido anteriormente esclarecido) para os cargos administrativos anteriormente exercidos; $19,5 \%$ destacam filiações partidárias anteriores e apenas 3,9\% informam as atividades intelectuais exercidas. Sublinhe-se aqui que a forma "narrativa" e não-sistemática de apresentação das informações sobre os parlamentares na maior parte das assembléias legislativas, sem a adoção de formulários-padrão - como ocorre no portal eletrônico da Câmara dos Deputados, por exemplo -, dificulta sobremaneira a organização de bases de dados prosopográficas a partir de tais fontes, tornando muitas vezes necessário um esforço interpretativo para a coleta de informações sobre tais itens.

A distribuição das informações mais relevantes sobre a socialização política pregressa dos deputados antes do exercício dos mandatos é dada pela Tabela 7:

TABELA 7 - TRAJETÓRIA POLÍTICA DOS DEPUTADOS ESTADUAIS (2003-2007)

\begin{tabular}{|c|c|c|c|c|c|c|c|c|c|c|c|c|c|c|}
\hline & \multicolumn{2}{|c|}{ PFC } & \multicolumn{2}{|c|}{ PFD } & \multicolumn{2}{|c|}{ PFE } & \multicolumn{2}{|c|}{ PPC } & \multicolumn{2}{|c|}{ PPD } & \multicolumn{2}{|c|}{ PPE } & \multicolumn{2}{|c|}{ TOTAL } \\
\hline & N. & $\%$ & N. & $\%$ & N. & $\%$ & $N$. & $\%$ & N. & $\%$ & N. & $\%$ & N. & $\%$ \\
\hline \multicolumn{15}{|l|}{ Legisłatura atual } \\
\hline Primeira legislatura & 91 & 46,7 & 122 & 535 & 73 & 57,9 & 102 & 49,0 & 55 & 42,6 & 99 & 57,2 & 542 & 51,2 \\
\hline Segunda legislatura & 33 & 169 & 35 & 15,4 & 21 & 16,7 & 42 & 20,2 & 24 & 18,6 & 35 & 20,2 & 190 & 17,9 \\
\hline Terceira legisatura & 29 & 149 & 35 & 15,4 & 11 & 8,7 & 25 & 12,0 & 27 & 20,9 & 23 & 13,3 & 150 & 14,2 \\
\hline Mais de quatro legisaturas & 42 & 215 & 36 & 158 & 21 & 16,7 & 39 & 18,8 & 23 & 17,8 & 16 & 9,2 & 177 & 16,7 \\
\hline Total & 195 & 100 & 228 & 100 & 126 & 100 & 208 & 100 & 129 & 100 & 173 & 100 & 1059 & 100 \\
\hline \multicolumn{15}{|c|}{ Ocupou cargoslegisativos? } \\
\hline Nẫo & 83 & 42,6 & 109 & 478 & 65 & 51,6 & 88 & 42,3 & 47 & 36,4 & 77 & 44,5 & 469 & 44,3 \\
\hline Sim & 112 & 57,4 & 119 & 522 & 61 & 48,4 & 120 & 57,7 & 82 & 63,6 & 96 & 55,5 & 590 & 55,7 \\
\hline Total & 195 & 100 & 228 & 100 & 126 & 100 & 208 & 100 & 129 & 100 & 173 & 100 & 1059 & 100 \\
\hline \multicolumn{15}{|c|}{ Ocupou cargos administrativos? } \\
\hline Nẫo & 129 & 662 & 164 & 719 & 88 & 69,8 & 144 & 69,2 & 72 & 55,8 & 116 & 67,1 & 713 & 67,3 \\
\hline $\operatorname{Sim}$ & 66 & 338 & 64 & 28,1 & 38 & 30,2 & 64 & 30,8 & 57 & 44,2 & 57 & 32,9 & 346 & 32,7 \\
\hline Total & 195 & 100 & 228 & 100 & 126 & 100 & 208 & 100 & 129 & 100 & 173 & 100 & 1059 & 100 \\
\hline \multicolumn{15}{|c|}{ Vhculos commovimentos associativos (desagregado) } \\
\hline Assistencialismo & 11 & 5,6 & 8 & 3,5 & 7 & 5,6 & 9 & 4,3 & 6 & 4,7 & 2 & 1,2 & 43 & 4,1 \\
\hline Associaçẫo corporativa & 1 & 0,5 & 5 & 2,2 & 2 & 1,6 & 3 & 1,4 & 1 & 0,8 & 1 & 0,6 & 13 & 1,2 \\
\hline Associaçẫo de classe & 11 & 5,6 & 14 & 6,1 & 6 & 48 & 10 & 4,8 & 5 & 3,9 & 4 & 2,3 & 50 & 4,7 \\
\hline Igrejas & 4 & 2,1 & 13 & 5,7 & 1 & 0,8 & 2 & 1,0 & 3 & 2,3 & 6 & 3,5 & 29 & 2,7 \\
\hline Movimerto estudartil & 0 & 0,0 & 1 & 0,4 & 0 & 0,0 & 5 & 2,4 & 0 & 0,0 & 9 & 5,2 & 15 & 1,4 \\
\hline Movimerto sindical & 1 & 0,5 & 0 & 0,0 & 5 & 40 & 4 & 1,9 & 1 & 0,8 & 42 & 24,3 & 53 & 5,0 \\
\hline Movimertos culturais & 1 & 0,5 & 0 & 0,0 & 0 & 0,0 & 0 & 0,0 & 0 & 0,0 & 0 & 0,0 & 1 & 0,1 \\
\hline Movimertos sociais & 3 & 1,5 & 2 & 0,9 & 2 & 1,6 & 5 & 2,4 & 0 & 0,0 & 13 & 7,5 & 25 & 2,4 \\
\hline Municipalismo & 2 & 1,0 & 1 & 0,4 & 2 & 16 & 3 & 1,4 & 2 & 1,6 & 0 & 0,0 & 10 & 0,9 \\
\hline Outros & 0 & 0,0 & 1 & 0,4 & 0 & 0,0 & 0 & 0,0 & 0 & 0,0 & 0 & 0,0 & 1 & 0,1 \\
\hline Sern informaçẫo & 161 & 82,6 & 183 & 803 & 101 & 80,2 & 167 & 80,3 & 111 & 86,0 & 96 & 55,5 & 819 & 77,3 \\
\hline Total & 195 & 100 & 228 & 100 & 126 & 100 & 208 & 100 & 129 & 100 & 173 & 100 & 1059 & 100 \\
\hline
\end{tabular}

FONTE: Braga (2007b). 
Ainda a respeito desse item, os dados obtidos permitem-nos apreender algumas diferenças entre os vários tipos de partidos políticos; embora pequenas, essas diferenças não devem ser desconsideradas, devendo servir de diretrizes para estudos futuros que usem estas fontes como base, quando informações satisfatórias sobre as elites políticas que dela fazem parte finalmente forem apresentadas na rede.

Assim, os PPE apresentam um elevado percentual de deputados cuja principal via de entrada na política deu-se por meio da atuação em movimentos sociais de diversas naturezas $(11,9 \%)$, movimento sindical (19,3\%) e estudantil (14,8\%), sendo que apenas $34,8 \%$ de seus parlamentares informaram em seus perfis o exercício do mandato legislativo como primeira atividade política formal exercida antes do mandato de deputado estadual. Em contraste, para a maior parcela dos demais partidos a principal via de entrada na política informada, ou pelo menos que se pode depreender da leitura do perfil, foram os mandatos legislativos, nos vários níveis de representação política, seguidos de cargos executivos, especialmente prefeitos ou secretários de cidades médias do interior, que conferem capital político para tais parlamentares candidatarem-se a deputados estaduais.

Outro dado que deve ser destacado da tabela anterior é o elevado percentual de parlamentares de partidos de esquerda que já ocuparam cargos administrativos (especialmente prefeitos e secretários municipais), revelando que tais parlamentares, longe de serem outsiders do sistema político, já possuíam uma certa experiência administrativa prévia, estando tais partidos longe de serem integrados por políticos socializados apenas em movimentos sociais ou de contestação da ordem vigente. A nosso ver, esse indicador reflete o progressivo processo de institucionalização da política brasileira, com os partidos de esquerda ocupando cargos nas esferas subnacionais de governo, que servem mesmo como um importante "trampolim" para a ocupação de postos eletivos em outras esferas do sistema político. Ou seja: já não se fazem mais outsiders como antigamente, parodiando o título de um conhecido texto de um estudioso do recrutamento político brasileiro (MARENCO, 2000).

Assim como no item anterior, derivamos como corolário do trabalho de coleta de dados um índice que consiste na média ponderada dos percentual de informações contidas sobre os deputados nos portais das assembléias, segundo o critério de relevância para nossa pesquisa e para a elaboração de nossa base de dados "prosopográfica". O desempenho de cada Assembléia Legislativa em relação às informações mais ou menos satisfatórias sobre a trajetória política de seus parlamentares é dado pelo gráfico abaixo:

\section{GRÁFICO 2 - INFORMAČ̃̃ES SOBRE TRAJETÓRIA POLÍTICA NOS PORTAIS DAS ASSEMBLÉIAS LEGISLATIVAS (MÉDIAPONDERADA)}

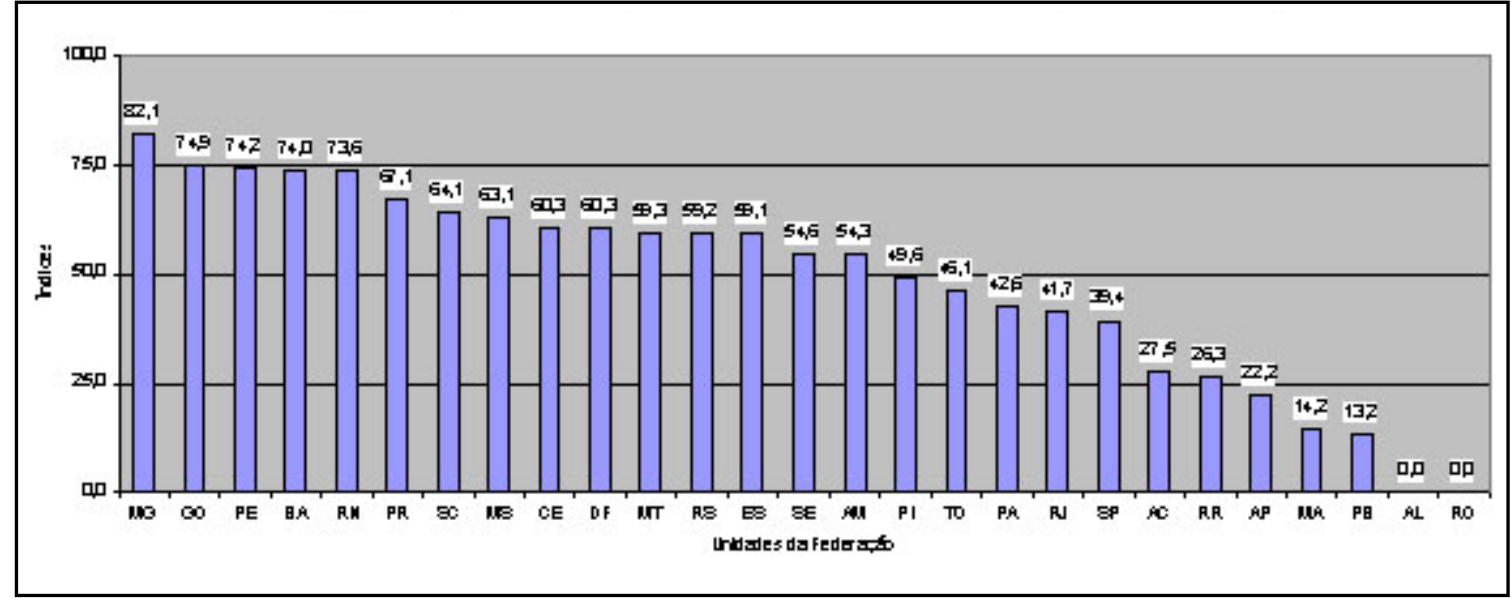

Como podemos observar, as informações sobre trajetória política e cargos anteriormente ocupados pelos parlamentares são razoavelmente abundantes nos portais, embora na maior parte das vezes sejam apresentadas de maneira incompleta, fragmentada e não-sistemática. Isso se deve 
ao fato dos parlamentares freqüentemente enfatizarem, em seus perfis, as realizações e obras efetuadas no exercício de mandatos anteriores, especialmente naqueles órgãos que não adotam formulários-padrão que obriguem os deputados a fornecer outras informações sistemáticas sobre sua trajetória política anterior, não necessariamente auto-apologéticas. Outrossim, foram justamente as assembléias que apresentaram em seus portais formulários-padrão com informações sobre a trajetória política que obtiveram maior pontuação no tocante a transparência e apresentação de informações sobre os parlamentares que dela fazem parte.

\section{COMPORTAMENTO POLÍTICO E PARLA- MENTAR DOS DEPUTADOS ESTADUAIS}

Neste momento da análise podemos formular a indagação crucial: para que estudar a composição e o recrutamento das elites político-partidárias e dos demais grupos de intervenção política de modo geral? Tal estudo, a nosso ver, teria menor importância heurística, correndo o risco de reduzir-se a uma mera sociografia descritiva dos grupos de intervenção política caso eventuais diferenças (renda, status e estrato social, patrimônio, nível educacional, perfil ideológico, valores cognitivos e trajetórias políticas, assim como eventuais processos de "ressocialização" devidos às carreiras nas instâncias partidárias) não interferissem de alguma forma nas e se correlacionassem com as múltiplas dimensões do comportamento político dos parlamentares, gerando diferenças significativas nas suas diferentes estratégias e nos seus padrões de comportamento observados nas várias esferas em que se dá sua atividade política e social. Não objetivamos, nos limites desse artigo, abordar nem de perto com sistematicidade uma questão dessa magnitude analítica, mas simplesmente fornecer algumas evidências que nos permitam formular algumas questões a esse respeito, especialmente no tocante às fontes em que podem ser obtidas informações nas assembléias para uma abordagem mais sistemática dessa questão ${ }^{11}$.

11 Ou seja, não basta afirmar a trivialidade de que "o recrutamento conta” para o desempenho das instituições sociais, mas desenvolver instrumentos teóricometodológicos para verificar, em cada processo político concreto, se e como se dá tal influência - problema que, como dissemos, não pode ser senão tangenciado neste texto. Por outro lado, a afirmação acima não equivale à propo-
Examinaremos em seguida alguns itens relevantes para o estudo do comportamento político dos deputados nas assembléias legislativas estaduais brasileiras. A partir das informações coletadas, podemos constatar que a maior parte dos deputados estaduais já apresenta endereço eletrônico para contato com o cidadão $(74,9 \%)$ e número de telefone na web $(68,7 \%)$, o que podemos considerar um percentual baixo, tendo em vista os recursos tecnológicos atualmente disponíveis, especialmente para quem tem acesso a verbas públicas. Mais grave ainda é o baixíssimo percentual de parlamentares com websites acessíveis a partir de seus perfis nas assembléias: apenas $176(16,6 \%)$ do total de deputados estaduais da $15^{\text {a }}$ Legislatura informaram ao cidadãointernauta endereço de seu website pessoal. Mais uma vez são os PPE que se singularizam em relação aos demais tipos de partido, apresentando um percentual mais elevado de deputados com websites pessoais $(31,8 \%)$. Por outro lado, ao contrário dos portais eletrônicos da Câmara dos Deputados e do Senado Federal, em nenhuma das assembléias há um vínculo eletrônico direto dos perfis pessoais dos deputados para o resultado das votações nominais ocorridas em plenário ou mesmo para a presença dos deputados às sessãos. Apenas a título de exemplo, o uso de websites por categoria de parlamentares poder ser ilustrado pela tabela a seguir: sição segundo a qual uma sociografia descritiva das elites seja destituída de importância analítica e não possa servir de base para análises em profundidade de processos políticos substantivos e como fator explicativo de determinadas trajetórias sociais. Ao contrário, nós mesmos procuramos empreender uma sociografia desse tipo em outro trabalho, bem como esclarecer de maneira sintética alguns de seus limites (BRAGA, 1998). 


\begin{tabular}{|c|c|c|c|c|c|c|}
\hline & \multicolumn{2}{|c|}{ SEM WEBSITE } & \multicolumn{2}{|c|}{ COM WEBSITE } & \multicolumn{2}{|c|}{ TOTAL } \\
\hline & $N$ & 听 & N. & 嗢 & N. & 吻 \\
\hline \multicolumn{7}{|c|}{ Campo ideológico } \\
\hline Centro & 340 & 84,2 & 64 & 15,8 & 404 & 100,0 \\
\hline Direita & 314 & 88,2 & 42 & 11,8 & 356 & 100,0 \\
\hline Esquerda & 230 & 76,9 & 69 & 23,1 & 299 & 100,0 \\
\hline Total & 884 & 83,5 & 175 & 16,5 & 1059 & 100,0 \\
\hline \multicolumn{7}{|c|}{ Tipo de partido } \\
\hline $\mathrm{PFC}$ & 164 & 84,1 & 31 & 15,9 & 195 & 100,0 \\
\hline PFD & 202 & 88,6 & 26 & 11,4 & 228 & 100,0 \\
\hline PFE & 110 & 87,3 & 16 & 12,7 & 126 & 100,0 \\
\hline PPC & 175 & 84,1 & 33 & 15,9 & 208 & 100,0 \\
\hline PPD & 113 & 87,6 & 16 & 12,4 & 129 & 100,0 \\
\hline PPE & 120 & 69,4 & 53 & 30,6 & 173 & 100,0 \\
\hline Total & 884 & 83,5 & 175 & 16,5 & 1059 & 100,0 \\
\hline \multicolumn{7}{|c|}{ Região do país } \\
\hline Centro-Oeste & 79 & 69,9 & 34 & 30,1 & 113 & 100,0 \\
\hline Nordeste & 308 & 90,3 & 33 & 9,7 & 341 & 100,0 \\
\hline Norte & 167 & 90,3 & 18 & 9,7 & 185 & 100,0 \\
\hline Sudeste & 208 & 76,8 & 63 & 23,2 & 271 & 100,0 \\
\hline Sul & 122 & 81,9 & 27 & 18,1 & 149 & 100,0 \\
\hline Total & 884 & 83,5 & 175 & 16,5 & 1059 & 100,0 \\
\hline \multicolumn{7}{|l|}{ Faixa Etária } \\
\hline 20 a 30 & 18 & 72,0 & 7 & 28,0 & 25 & 100,0 \\
\hline 31 a 40 & 76 & 76,0 & 24 & 24,0 & 100 & 100,0 \\
\hline 41 a 50 & 154 & 80,2 & 38 & 19,8 & 192 & 100,0 \\
\hline 51 a 60 & 108 & 83,7 & 21 & 16,3 & 129 & 100,0 \\
\hline Mais de 61 & 24 & 88,9 & 3 & 11,1 & 27 & 100,0 \\
\hline Total & 380 & 80,3 & 93 & 19,7 & 473 & 100,0 \\
\hline
\end{tabular}

FONTE: Braga (2007b).

Pela tabela acima podemos observar algumas diferenças que, embora pequenas, são significativas no uso de websites por categoria de parlamentares. Assim, parlamentares do campo político de esquerda (23,1\%), eleitos por partidos programáticos desse mesmo campo (30,6\%), da região Centro-Oeste do país $(30,1 \%)$ e com menos de 40 anos (26,0\%) apresentam uma freqüência maior de uso da internet para divulgar suas atividades políticas, o que pode ser considerado um indicador de uma preocupação maior com a transparência de suas ações. Se se trata de um fenômeno passageiro, limitado aos estágios iniciais de uso da web pelos deputados estaduais, ou um processo de mais longa duração, apenas estudos futuros poderão responder de maneira taxativa.

Dessas variáveis sobre comportamento político podemos derivar os gráficos abaixo, que ilustram o grau de disponibilidade de informações relevantes para o estudo do comportamento políti- co dos parlamentares nas assembléias legislativas, tanto por meio da visita aos perfis parlamentares dos próprios deputados, quanto por meio da visita aos websites das casas legislativas (cf. Anexo 2). Agrupamos as variáveis referentes ao "comportamento político" dos parlamentares em dois subgrupos: i) aquelas informações cuja disponibilidade depende predominantemente de políticas institucionais adotadas pelas casas legislativas e que apresentam pouca variação entre os parlamentares individualmente considerados, como disponibilidade de endereço eletrônico, telefone e outros dados institucionais dos deputados; ii) aqueles dados que estão sob controle mais estrito dos políticos individualmente considerados, como blogs e websites pessoais, taxa de resposta às mensagens eletrônicas enviadas, informativos pessoais, vínculos de notícias atualizado e outras variáveis sobre as quais os deputados e seus gabinetes possuem maior grau de controle. 
GRÁFICO 3-COMPORTAMENTO POLÍTICO DOS DEPUTADOSAPARTIR DOS PORTAIS DAS ASSEMBLÉIAS LEGISLATIVAS (MÉDIAPONDERADA)

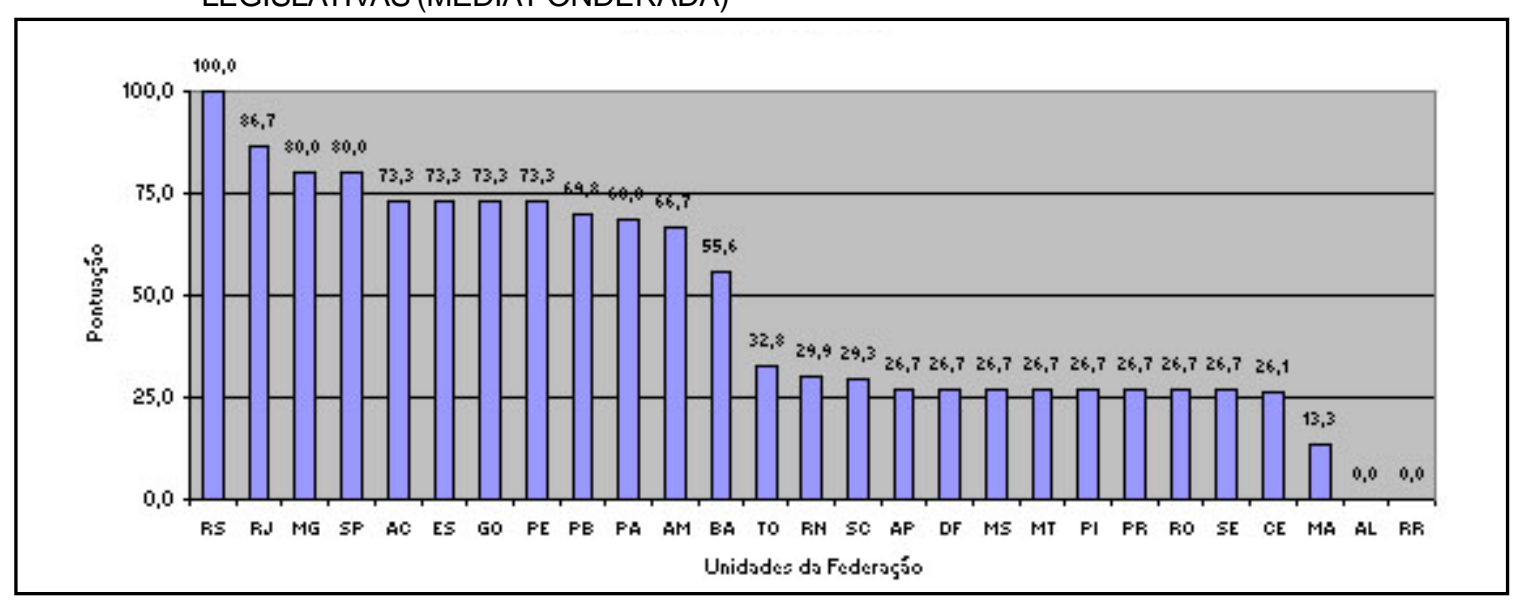

É importante esclarecermos que muitas das informações a que não pudemos ter acesso diretamente por meio dos perfis dos deputados podem sê-lo por meio dos portais das casas parlamentares, embora essa última modalidade de acesso denote uma preocupação menor com a transparência da gestão de tais órgãos que com o disponibilidade simples e fácil do acesso direto ${ }^{12}$. Destaque-se a esse respeito o portal da Assembléia Legislativa do Rio Grande do Sul, o único legislativo que recebeu pontuação máxima, reve- lando assim um elevado grau de preocupação com a transparência de seu processo decisório e de disponibilização para a opinião pública de informações que possibilitem ao eleitor averiguar e monitorar as várias dimensões do comportamento dos deputados estaduais.

No tocante aos grau de disponibilidade de informações sobre o comportamento político que podem ser obtidas a partir dos portais parlamentares, seu desempenho é o seguinte:

\section{GRÁFICO 4 - INFORMAÇÕES SOBRE COMPORTAMENTO POLÍTICO DOS PARLAMENTARES A PARTIR} DOS PORTAIS DOS DEPUTADOS (MÉDIAS PONDERADAS)

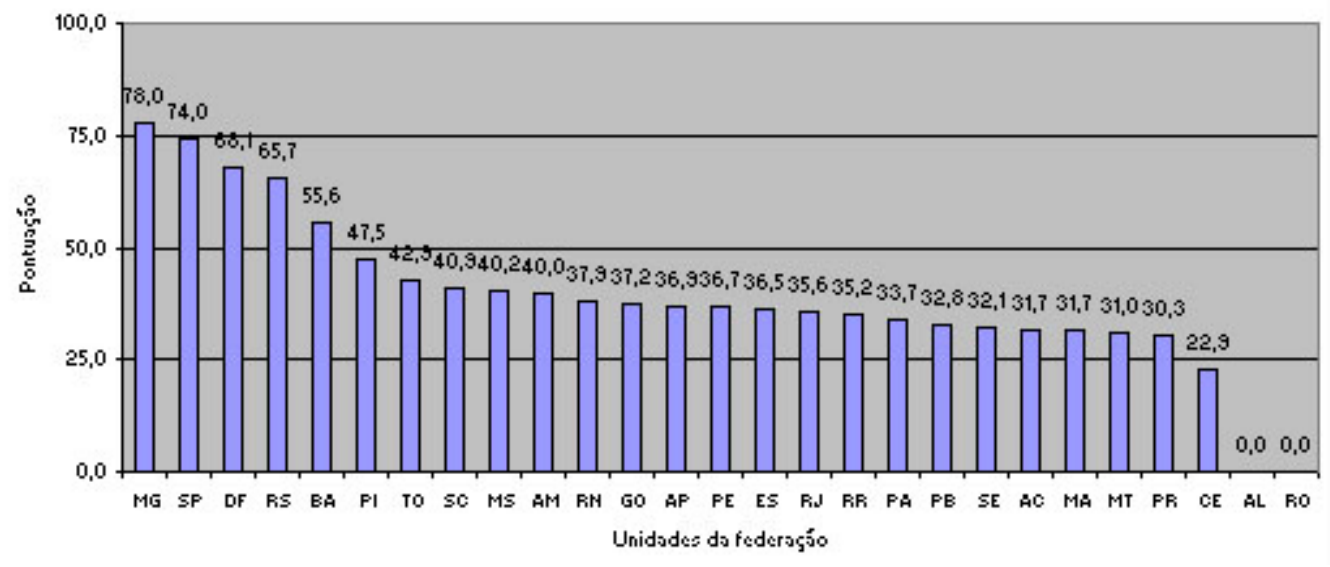

12 Sublinhe-se de passagem que a mera existência ou não de portais não pode ser considerado o indicador mais preciso sobre eventuais diferenças do uso na internet pelos diferentes segmentos das elites parlamentares. Seria necessário investigar o próprio conteúdo de cada portal, assim como outras variáveis destinadas a mensurar o grau de interatividade e de transparência dos parlamentares com a opinião pública a partir de suas páginas pessoais. Estamos efetuando uma pesquisa desse tipo para os parlamentares da $16^{a}$ Legislatura. Entretanto, não foi possível fazê-la para os parlamentares da legislatura anterior. 
O gráfico anterior indica o grau de informação disponível sobre o comportamento dos parlamentares a partir de seus perfis contidos nos portais legislativos. Apenas cinco assembléias atingiram níveis razoáveis de transparência, indicando que muitas informações básicas e elementares sobre a atuação dos deputados não continua à disposição da opinião pública e do cidadão-internauta para acesso rápido e eficiente na maioria das casas legislativas brasileiras. Como as informações sobre o comportamento político dos deputados dependem mais da postura de cada deputado e de sua assessoria de oferecer ou não tais informações, a distribuição do desempenho dos índices é mais heterogênea do que no item anterior. Verificamos que apenas a Assembléia Legislativa de Minas Gerais atingiu um excelente desempenho, o que nos permite inferir que ainda é bastante reduzido o compromisso dos deputados estaduais brasileiros com a divulgação de informações transparentes sobre sua conduta por meio de suas páginas individuais. Como indicamos em pesquisas anteriores sobre o caso do Paraná (BRAGA, 2006), menos do que problemas técnicos são os valores políticos dos deputados e o tipo de postura por eles adotados em relação à internet os principais responsáveis por esse tipo de comportamento. Assim sendo, apenas a pressão social e a detecção sistemática de tais problemas pode melhorar o grau de transparência e o desempenho dos portais parlamentares nesse sentido.

\section{CONCLUSÃO}

Como conclusão, podemos acrescentar um gráfico consolidando as informações existentes sobre o grau de informatização, as biografias e a ação dos parlamentares constantes das casas legislativas estaduais brasileiras, assim como tecendo algumas considerações sobre o potencial de tal fonte para o estudo das elites parlamentares de tais unidades da federação.

O grau de transparência dos legislativos brasileiros, medido pela apresentação de informações sobre os parlamentares da legislatura (2003-2007), é-nos dado pelo gráfico abaixo, que resume o nível de informações existentes sobre os parlamentares e as variáveis de perfil, trajetória e comportamento que empregamos para analisar os sites dos deputados.

\section{GRÁFICO 5 - ÍNDICE GLOBAL DE TRANSPARÊNCIA DOS LEGISLATIVOS ESTADUAIS}

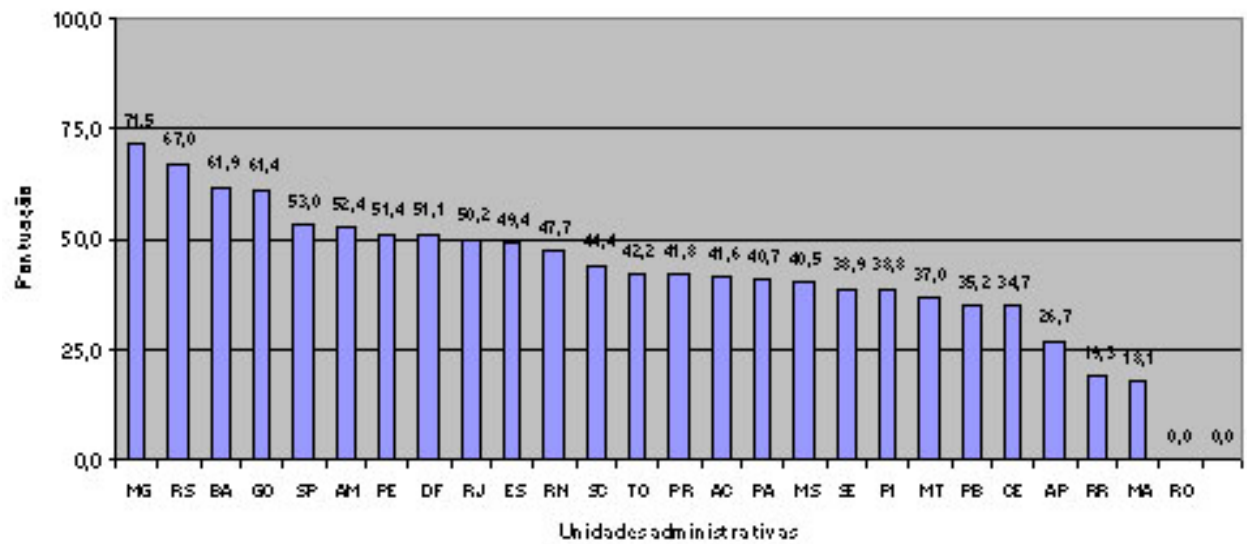

Pelo gráfico, podemos perceber que apenas 9 das 27 casas legislativas apresentam pontuação acima da média, constituindo-se assim em fontes razoavelmente confiáveis para o estudo das elites parlamentares que dela fazem parte. Ou seja: na realidade, a internet e os portais parlamentares ain- da estão longe de constituírem-se fontes principais para a construção de bases de dados prosopográficas confiáveis de natureza análoga à que ocorre em relação à Câmara dos Deputados, que se constitui em fonte importante para vários estudos sobre os deputados em nível nacional anteriormente mencionados. 
Podemos afirmar ainda que o uso do enfoque prosopográfico a partir dos websites dos legislativos estaduais brasileiros apresenta vantagens e desvantagens em comparação com outras fontes e métodos empregados para o estudo das elites e grupos de intervenção política. Dentre as vantagens ou os aspectos positivos, podemos mencionar a possibilidade de estudar a população inteira de cada legislativa de uma determinada legislatura; a possibilidade de articular múltiplas variáveis de pesquisa e de analisar o comportamento político dos deputados a partir das fontes primárias e, também, a maior independência do analista em relação às suas fontes, permitindo ainda uma maior verificabilidade dos dados coletados por outros pesquisadores e a reprodutibilidade dos resultados obtidos por cada analista.

Dentre os aspectos negativos ou desvantagens, devemos destacar o caráter ainda precário dos portais eletrônicos da maior parte das casas legislativas brasileiras, especialmente em nível subnacional; a ausência de formulários-padrão para a apresentação mais sistemática das informações biográficas sobre os parlamentares; a relutância da maior parte desses políticos em criarem portais pessoais com níveis satisfatórios de informação e sua tendência em transformar seus portais em "vitrines virtuais", ocultando informações que podem ser relevantes para o especialista e, especialmente, para o cidadão-internauta interessado em um conhecimento mais aprofundado sobre a origem e o comportamento político dos políticos que elegeu.

Enfim, os portais da maior parte das assembléias legislativas ainda não apresentam informações satisfatórias para o estudo das elites parlamentares estaduais e devem ser utilizados como fontes complementares, articuladas a outras, tanto "frias" como "quentes", como as fichas eleitorais do TSE e dos tribunais regionais eleitorais (TRÊS), dicionários biográficos, surveys e entrevistas em profundidade, que têm sido utilizadas com proveito por vários analistas para o estudo das elites políticas de uma maneira geral, não apenas parlamentares. Segundo nosso ponto de vista, no atual estágio do grau de informatização dos legislativos estaduais brasileiros os portais das assembléias legislativas apenas devem ser usados como principal e exclusiva fonte de pesquisa quando o objeto e o objetivo da investigação forem os próprios portais legislativos e as informações nele disponíveis.

Para finalizar, agregamos um anexo contendo uma sugestão de planilha ou ficha biográfica para a apresentação de algumas informações básicas ao cidadão-internauta e ao pesquisador sobre seu representante eleito ${ }^{13}$. Acreditamos que é a partir da apresentação progressiva de tais informações nos portais legislativos que se pode estimular e tornar mais eficaz a interação e a comunicação entre elites parlamentares e opinião pública, bem como a participação dos cidadãos na atividade parlamentar e governativa usando os recursos propiciados pela internet.

\footnotetext{
13 Essa planilha foi elaborada para o Sistema de Monitoramento e Avaliação dos Eleitos (SMAE) - programa desenvolvido pela Federação das Indústrias do Estado do Paraná (FIEP) em convênio com a UFPR - e está sendo aplicada no acompanhamento das atividades de segmentos das elites políticas paranaenses. Uma sua versão ligeiramente modificada está disponível para consulta pública no portal do programa (SMAE, s/d).
}

Sérgio Soares Braga (ssbraga@ufp.br) é Doutor em História Econômica pela Universidade Estadual de Campinas (Unicamp) e Professor do Departamento de Ciências Sociais da Universidade Federal do Paraná (UFPR).

Maria Alejandra Nicolás (alejandranicolas@gmail.com) é Mestranda em Sociologia na Universidade Federal do Paraná (UFPR).

\section{REFERÊNCIAS BIBLIOGRÁFICAS}

ANASTASIA, F.; CORREA, I. \& NUNES, F. 2005. Caminhos, veredas e atalhos: legislativos estaduais e trajetórias políticas. Brasília : Interlegis. Disponível em : http:// www.interlegis.gov.br/processo_legislativo/ 20050124115411/. Acesso em : 15.mar.2008.
BOSCHI, R.; DINIZ, E. \& SANTOS, F. 2000. Elites políticas e econômicas no Brasil contemporâneo: a desconstrução da ordem corporativa e o papel do Legislativo no cenário pós-reformas. São Paulo: Fundação Konrad Adenauer. 
BRAGA, S. 1998. Quem foi quem na Assembléia Constituinte de 1946. Brasília : Câmara dos Deputados.

2002. Elites políticas e alternativas de desenvolvimento na redemocratização de 19451946. História Econômica e História de Empresas, São Paulo, v. 2, p. 75-106, $2^{\circ}$ sem.

2007a. O papel das TICs na institucionalização das democracias : um estudo sobre a informatização dos órgãos legislativos na América do Sul com destaque para o Brasil. Brasília : Plenarium. Disponível em : http://www2.camara.gov.br/internet/eve/ realizados/portal_seminario2007/material.html. Acesso em : 25.abr.2007.

2007b. Planilha prosopográfica a partir dos websites das assembléias legislativas brasileiras. Curitiba : Grupo de Pesquisa Democracia e Instituições Políticas.

CARDOSO, G. \& MORGADO, A. 2003. A comunicação política na sociedade da informação : elites parlamentares e internet. Lisboa : s/n. Disponível em : http://iscte.pt/ galc/ Texto_6.pdf. Acesso em : 12.maio.2008.

CASTELLS, M. 2003. A galáxia internet : reflexões sobre a internet, os negócios e a sociedade. Rio de Janeiro : Zahar.

CUNHA, M. A. 2005. Meios eletrônicos e transparência : a interação do Vereador brasileiro com o cidadão e o poder Executivo. Artigo presentado no X Congreso Internacional del CLAD sobre la Reforma del Estado y de la Administración Pública, ocurrido en Santiago do Chile, de 18 a 21 de octubre. Digit.

DADER, J. L. 2003. Ciberdemocracia y ciberparlamento. El uso de correo electrónico entre los parlamentarios espanõles y ciudadanos comunes (1999-2001). Telos, Madrid, n. 55, p. 86-96, abr.-jun. Disponível em : http://www.campusred.net/telos/ articuloexperiencia. asp?idarticulo=1\&rev=55. Acesso em : 15.abr.2008.

FIGUEIREDO, A. \& LIMONGI, F. 1999. Executivo e Legislativo na nova ordem constitucional. Rio de Janeiro: FGV.

FLEISCHER, D. 1976. Thirty Years of Legislative Recruitment in Brazil. Brasília : UNB.
FRANÇA, A. S. T.; MARTINS, F. R. S. \& BRAGA, S. 2006. Internet, democracia e política num ano eleitoral. Paraná Eleitoral, Curitiba, n. 60, p. 37-68, abr.-jun.

HEINZ, F. (org.). 2006. Por outra História das Elites. Rio de Janeiro : FGV.

LIMA JR., O. B. \& CAMARGO, M. B. 1997. O Legislativo mineiro : democratização, perfil sociopolítico e decisões legislativas (19831988). Teoria e Sociedade, Belo Horizonte, $\mathrm{n}$. 1, p. $169-189,1^{\circ}$ sem.

LOVE, J. 1982. A locomotiva. São Paulo e a federação brasileira. São Paulo : Paz e Terra.

MARENCO, A. 2000. Não se fazem mais oligarquias como antigamente : recurtamento parlamentar, experiência política e vínculos partidários entre deputados brasileiros (19461998). Porto Alegre. Tese (Doutorado em Ciência Política). Universidade Federal do Rio Grande do Sul.

MARENCO, A. \& SERNA, M. 2007. Por que carreiras políticas na esquerda e na direita não são iguais? Recrutamento legislativo em Brasil, Chile e Uruguai. Revista Brasileira de Ciências Sociais, São Paulo, v. 22, n. 64, p. 93-113. Disponível em: http://www.scielo.br/ pdf/rbcsoc/v22n64/a08v2264.pdf. Acesso em: 15.mar.2008.

MARQUES, F. P. J. 2007. Níveis de participação dos cidadãos na internet : um exame dos websites de senadores brasileiros e norte-americanos. Trabalho apresentado no XVI Encontro da Associação Nacional de Programas de Pós-Graduação em Comunicação, realizado em Curitiba (Paraná), de 13 a 16 de junho. Digit.

MESSENBERG, D. 2002. A elite parlamentar do pós-constituinte: atores e práticas. São Paulo: Brasiliense.

2007. A elite parlamentar brasileira (19892004). Sociedade e Estado, Brasília, v. 22, n. 2, p. 309-370, maio-ago.

MICELI, S. 1986. Carne o osso da elite política brasileira pós-1930. In : FAUSTO, B. (org.). História geral da civilização brasileira. T. III : O Brasil republicano. V. 3 : Sociedade e política (1930-1964). $3^{\mathrm{a}}$ ed. São Paulo : Difel. 
NORRIS, P. 2001. Digital Divide. Civic Engagement, Information Poverty, and the Internet Worldwide. Cambridge : Cambridge University.

PERISSINOTTO, R.; CODATO, A.; BRAGA, S. \& FUKS, M. 2007. Quem governa? Um estudo das elites políticas do Paraná. Curitiba : UFPR.

RODRIGUES, F. 2006. Políticos do Brasil. São
Paulo : Publifolha.

RODRIGUES, L. M. 2002. Partidos, ideologia e composição social. Revista Brasileira de Ciências Sociais, São Paulo, v. 17, n. 48, p. 3147. Disponível em: http://www.scielo.br/pdf/ rbcsoc/v17n48/13948.pdf. Acesso em: 15.mar.2008.

2006. Mudanças na classe política brasileira. São Paulo : Publifolha.

\section{OUTRAS FONTES}

SMAE. s/d. Sistema de monitoramento e avaliação dos eleitos. Curitiba : Federação das Indústrias do Estado do Paraná. Disponível em : http://www.fieppr.org.br/redeempresarial/ monitora/. Acesso em : 15.maio.2008.
TSE. 2008. Tribunal Superior Eleitoral. Disponível em: http://www.tse.gov.br/internet/ index.html. Acesso em: 15.mar.2008.

\section{ANEXO 1 - MODELO DE FICHA BIOGRÁFICA COM INFORMAÇÕES BÁSICAS SOBRE ELITES PARLAMENTARES}

\begin{tabular}{|c|c|}
\hline \multicolumn{2}{|c|}{ MODELO DE PERFIL PARLAMENTAR } \\
\hline $\begin{array}{l}\text { FOTO DO } \\
\text { PARLAMENTAR }\end{array}$ & $\begin{array}{l}\text { Nome completo: } \\
\text { Nome parlamentar: } \\
\text { Partido: } \\
\text { Gabinete: } \\
\text { Fone: } \\
\text { Email: } \\
\text { Website pessoal: }\end{array}$ \\
\hline \multicolumn{2}{|c|}{$\begin{array}{l}\text { Nascimento: } \\
\text { Local de nascimento: } \\
\text { Estado Civil: } \\
\text { Profissōes: } \\
\text { Filiação: } \\
\text { Escolaridade dos pais: } \\
\text { Profissão dos pais: } \\
\text { Estudos e Graus Universitários: } \\
\text { Atividades Profissionais: } \\
\text { Religião: }\end{array}$} \\
\hline \multicolumn{2}{|c|}{$\begin{array}{l}\text { Forma de entrada na politica: } \\
\text { Trajetória Politica: } \\
\text { Legislaturas: } \\
\text { Filiaçōes Partidárias: } \\
\text { Cargos executivos e administrativos ocupados: } \\
\text { Atividades Parlamentares na atual legislatura: }\end{array}$} \\
\hline \multicolumn{2}{|c|}{$\begin{array}{l}\text { Vinculos com associaçöes civis e políticas: } \\
\text { Atividade intelectual: }\end{array}$} \\
\hline $\begin{array}{l}\text { Total de votos: } \\
\text { Soma de receitas dec } \\
\text { Soma das despesas } \\
\text { Soma dos bens decla }\end{array}$ & \\
\hline
\end{tabular}




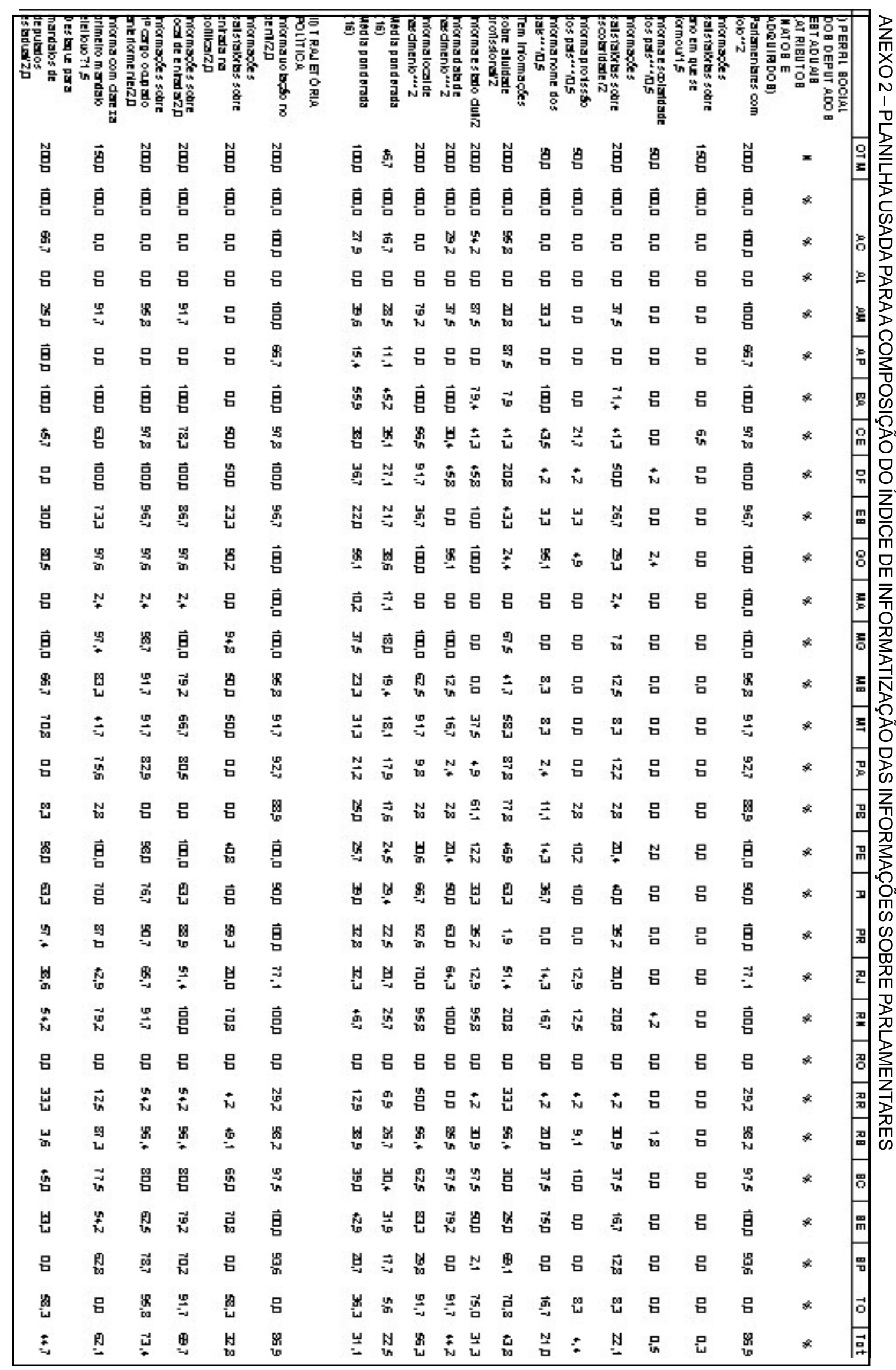




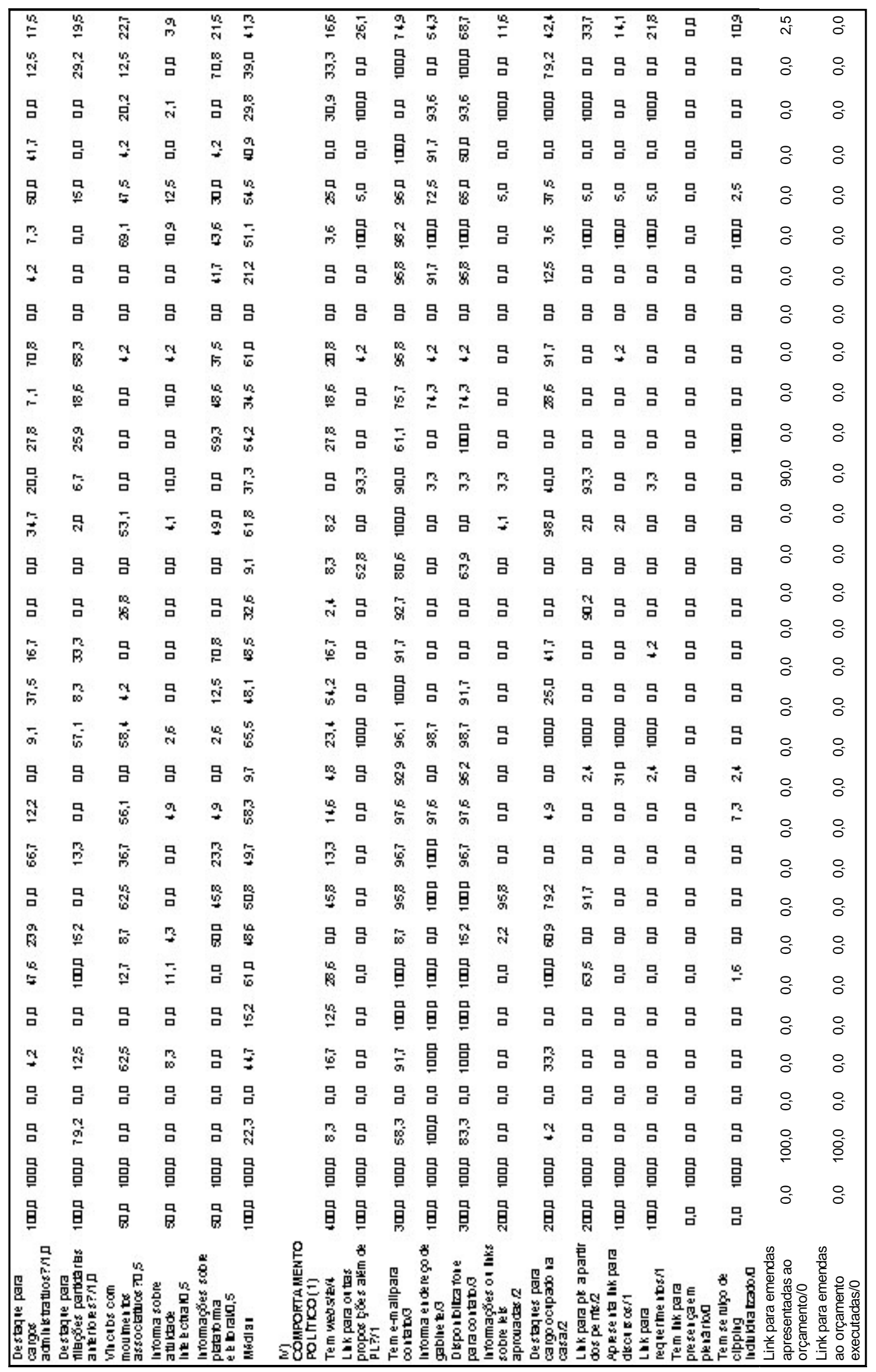




\begin{tabular}{|c|c|c|c|c|c|c|c|c|c|c|c|c|c|c|c|c|c|}
\hline & 离 & 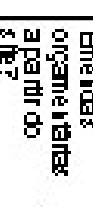 & & 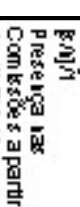 & 列 & & 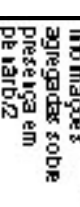 & & & 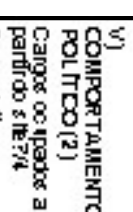 & & 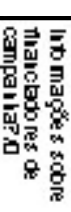 & & 星 & 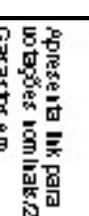 & $\begin{array}{l}0 \\
0\end{array}$ & 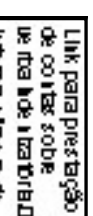 \\
\hline 㿠 & $\overrightarrow{\mathrm{g}} \overrightarrow{\mathrm{g}}$ & 吕 & 吕 & 吕 & 畐 & 宿 & 罟 & 苜 & 直 & 直 & 宫宫 & 吕 & 吕 & 吕 & 品铋 & 吕 & 믐 \\
\hline 百 & 宫宫 & 畐 & $\overrightarrow{\mathrm{g}}$ & $\overrightarrow{\mathrm{g}}$ & 哆 & $\overrightarrow{\mathrm{g}}$ & $\overrightarrow{\mathrm{B}}$ & 菑 & 菑 & $\overrightarrow{\mathrm{B}}$ & $\overrightarrow{\mathrm{\theta}} \overrightarrow{\mathrm{g}}$ & 宫 & 晿 & $\overrightarrow{\mathrm{g}}$ & $\overrightarrow{\mathrm{g}}$ & $\overrightarrow{\mathrm{g}}$ & $\overrightarrow{\mathrm{g}}$ \\
\hline$\stackrel{\vec{m}}{\underline{\underline{a}}}$ & 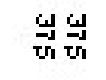 & 吕 & 믐 & 吕 & 吕 & 吕 & 믐 & $\overrightarrow{\mathrm{g}}$ & $\overrightarrow{\mathrm{g}}$ & $\overrightarrow{\mathrm{B}}$ & $\underset{N=-1}{\vec{N}} \mathbb{N}$ & 吕 & 믐 & 믐 & 吕 & 吕 & 吕 \\
\hline 吕 & 品品 & 吕 & 吕 & 吕 & 吕 & 吕 & 吕 & $\begin{array}{l}\text { 吕 } \\
\text { 等 }\end{array}$ & $\begin{array}{l}\text { 吕 } \\
\text { 等 }\end{array}$ & 吕 & 믐ㅁㅁㅁ & 品 & 믐 & 믐 & 吕 & $=$ 吕 & \\
\hline 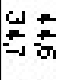 & 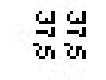 & 吕 & 吕 & 吕 & 吕 & 吕 & 宫 & 믐 & 宫 & $\overrightarrow{\mathrm{g}}$ & $\vec{ت}$ & 몸 & 吕 & 品 & 品 & $=$ 品 & \\
\hline 富 & 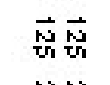 & 吕 & 몸 & 뭄 & 吕 & 몸 & 믐 & 몸 & 믐 & 哆 & क्ञात & 믐 & 믐 & 몸 & 吕 & 吕 & 5 \\
\hline 5 & 염염 & 吕 & 吕 & 뭄 & 뭄 & 몸 & 吕 & $\frac{9}{60}$ & $\frac{9}{b}$ & 喜 & $\underline{g}$ & 吕 & 吕 & 믐 & 吕罷 & 吕 & 듬 \\
\hline 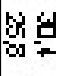 & $\underset{N}{\vec{N}} \vec{N}$ & 吕 & 吕 & 몀 & 吕 & 品 & 吕 & 吕 & 吕 & & ๘ & 吕 & 吕 & 吕 & 品 & 尊吕 & \\
\hline 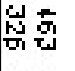 & 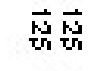 & 吕 & 吕 & 吕 & 吕 & ㅁ & 吕 & 吕 & 믐 & 首 & 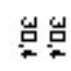 & 吕 & 믐 & 吕 & 믐 무 & 虽品 & \\
\hline 等 & 骂名 & 旦 & 宫 & 뭄 & 몸 & 몸 & 몸 & 畐 & $\overrightarrow{\mathrm{B}}$ & 宫 & 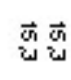 & 吕 & 몸 & 몸 & 品 & 男吕 & \\
\hline 5 & 의 4 & 吕 & 吕 & 맘 & ㅁㅁㅁ & 品 & 믐 & $\overrightarrow{\mathrm{g}}$ & $\overrightarrow{\mathrm{B}}$ & 宫 & 晏离 & 吕 & 吕 & 吕 & 品 & 8 吕 & \\
\hline 20 & 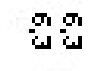 & 品 & 吕 & 뭄 & 믐 & $\bar{\xi}$ & 吕 & 믐 & 吕 & 믑 & 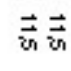 & 뭄 & 吕 & 믐 & 吕 $\bar{x}$ & $=$ 吕 & \\
\hline 2 & 总名 & 吕 & 몸 & 뭄 & 吕 & & 吕 & 豆 & 豆 & & 要畐 & 吕 & ㅁ & 吕 & 吕 & 5 吕 & \\
\hline 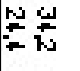 & 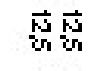 & 吕 & 吕 & 뭄 & 믐 & & 믐 & 믐 & 믐 & & 可产 & 吕 & 吕 & 믐 & 吕 & 容吕 & \\
\hline 晋 & $\vec{W}$ & 吕 & 吕 & 吕 & 吕 & 吕 & 吕 & 吕 & 吕 & $\overrightarrow{\mathrm{g}}$ & $\Rightarrow$ & 吕 & 吕 & 吕 & 品 & E 品 & \\
\hline $5=5$ & 岁台 & 吕 & 吕 & ㅁㅁㅁ & 믐 & 吕 & 믐 & 总 & 总 & $\overrightarrow{\mathrm{g}}$ & 选 & 吕 & 吕 & 品 & 品 & 吕 & \\
\hline 焉 & $\mathscr{y}$ & 吕 & 몸 & 믐 & 믐 & $\frac{5}{5}$ & 吕 & $\stackrel{\underline{J}}{ }$ & $\stackrel{\underline{g}}{=}$ & 言 & 亮喜 & 맘 & 몸 & 吕 & 吕 & 묨몽 & 吕 \\
\hline 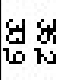 & 의 의 & 吕 & 맘 & 뭄 & 吕 & 吕 & 吕 & 言 & 喜 & 言 & 亮亮 & 吕 & 吕 & 몸 & 吕 & 品 吕 & 몸 \\
\hline 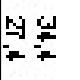 & $\vec{W}$ & 吕 & 뭄 & 뭄 & 吕 & 吕 & 吕 & 몽 & 몸 & 言 & 絗爫 & 吕 & 吕 & 몸 & 吕 & 몸 & 몸 \\
\hline 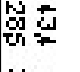 & $\overrightarrow{\mathrm{W}} \overrightarrow{\mathrm{v}}$ & 吕 & 吕 & 吕 & 吕 & 吕 & 吕 & 吕 & 吕 & 宫 & $\vec{E} \vec{z}$ & 吕 & 吕 & 吕 & 吕 모 & 品品 & 吕 \\
\hline 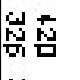 & 䏸䏸 & 吕 & 吕 & 吕 & 吕 & 吕 & $\overrightarrow{\mathrm{g}}$ & $\overrightarrow{\mathrm{g}}$ & $\overrightarrow{\mathrm{g}}$ & $\overrightarrow{\mathrm{g}}$ & 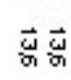 & 品 & 吕 & 吕 & 品 $x^{2}$ & 2 吕 & 品 \\
\hline$t \pi$ & 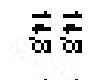 & 吕 & 吕 & 뭄 & 吕 & g & 吕 & g. & 品 & $\overrightarrow{\mathrm{g}}$ & $\overrightarrow{\vec{\omega}} \overrightarrow{\mathrm{w}}$ & 吕 & 吕 & 吕 & 品 $\frac{\pi}{2}$ & 즐 品 & 吕 \\
\hline لـ & $\vec{W} \vec{w}$ & 吕 & 吕 & ㅁㅁㅁ & 믐 & 吕 & 믐 & 믐 & 吕 & 喜 & 몸몽 & 몸 & 吕 & 吕 & 吕 I $^{\circ}$ & 졍 吕 & 吕 \\
\hline 通 & 吕吕 & 믐 & 吕 & 뭄 & 吕 & 믐 & 몸 & 믐 & 吕 & 몸 & 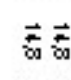 & 吕 & 몸 & 몸 & 吕 $\frac{x}{\pi}$ & 秝 吕 & 吕 \\
\hline 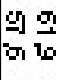 & 哆昆 & 旦 & 宫 & 宫 & 亩 & 熍 & 宫 & 菑 & 稟 & 哆 & 点点 & 吕 & 吕 & 吕 & 吕 & 君吕 & 吕 \\
\hline كال & $\vec{E}$ & 吕 & 吕 & 吕 & 吕 & 告 & 吕 & g & 告 & 菑 & $\overrightarrow{\underline{a}} \overrightarrow{\vec{g}}$ & 吕 & 吕 & 吕 & 吕 8 & 8 吕 & 品 \\
\hline $\begin{array}{l}394 \\
1 \mathrm{~s}\end{array}$ & $\overrightarrow{\mathrm{N}} \overrightarrow{\mathrm{n}} \overrightarrow{\mathrm{N}}$ & 吕 & 吕 & 吕 & 吕 & 吕 & 吕 & 吕 & 吕 & 豆 & $\overrightarrow{\underline{N}} \overrightarrow{\underline{N}}$ & 吕 & 吕 & 吕 & 吕鼻 & 輀 品 & 品 \\
\hline 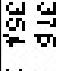 & 赔氮 & 吕 & 吕 & 뭄 & 喜 & 吕 & 吕 & 吉 & 喜 & 吉 & 点点 & 몸 & 믐 & 믐 & & 6 吕 & 言 \\
\hline 吾 & $\overrightarrow{\underline{g}} \vec{g}$ & 吕 & 몸 & 吕 & 吕 & is & 믐 & $\overrightarrow{\vec{N}}$ & $\overrightarrow{⿱ \vec{D}}$ & 喜 & $\begin{array}{l}\vec{b}, \vec{b} \\
\sigma \\
\sigma\end{array}$ & 吕 & 吕 & 吕 & 吕 & 몸 & ㅁ \\
\hline 列 & $\begin{array}{r}8 \\
8 \\
2\end{array}$ & 自 & 㖞 & & $\overrightarrow{\underline{\Xi}}$ & 它 & $\overrightarrow{\underline{\Xi}}$ & $\stackrel{n}{*}$ & $\stackrel{n}{*}$ & 吾 & 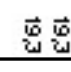 & 吕 & 吕 & 吕 & 吕 & 䀳吕 & \\
\hline
\end{tabular}

Artigo modificado por solicitação do editor em (Abril/2009). 